UC-NRLF || ||||||||||||||||||||||| +5 2 263 806

in

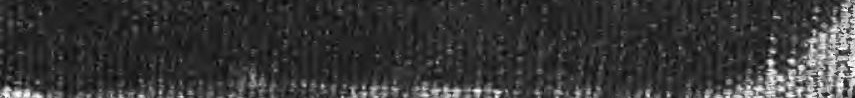



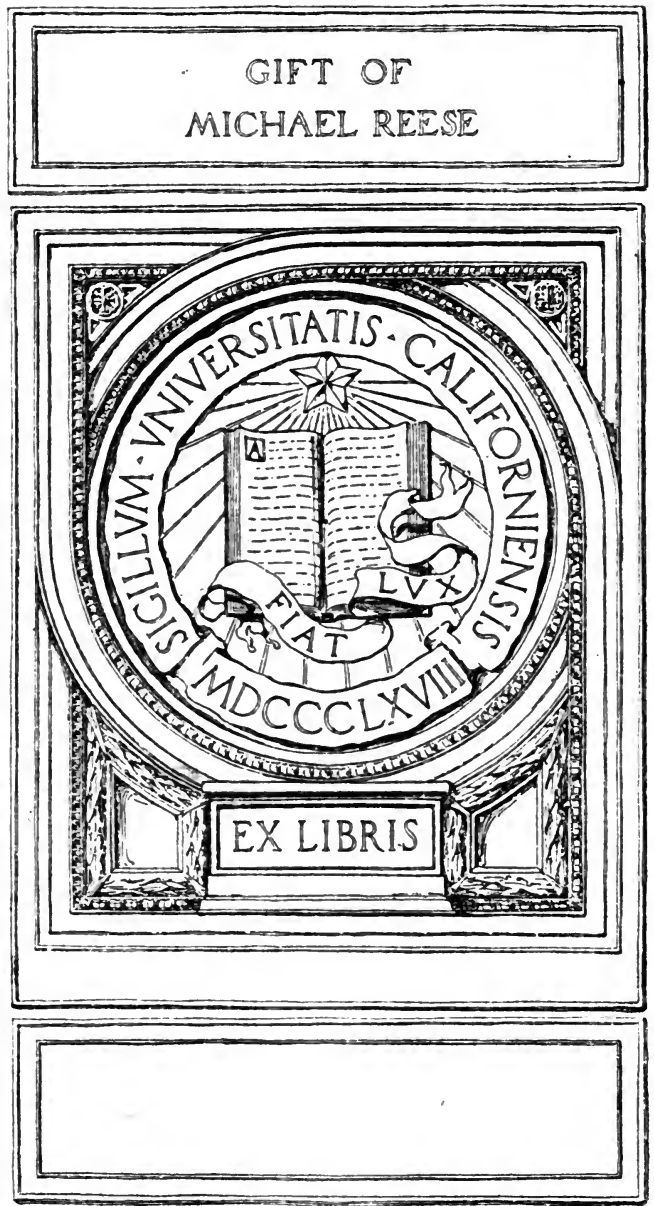


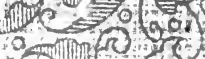

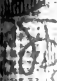

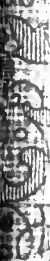
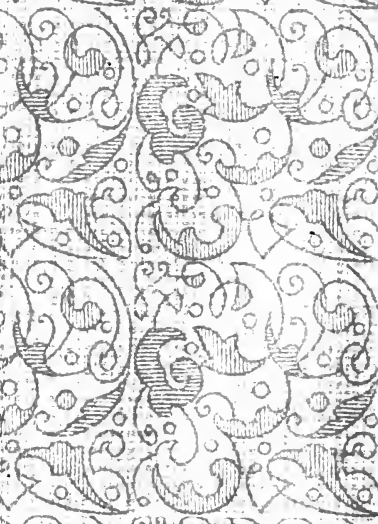

(a)
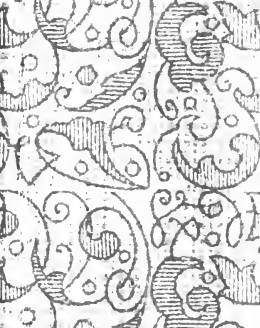

(1)
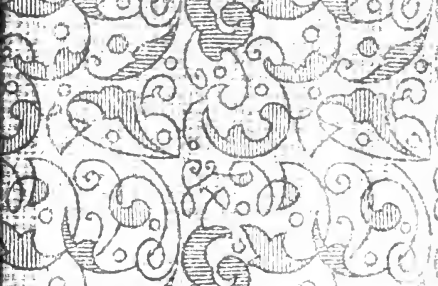

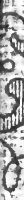

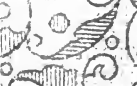

$\times$.
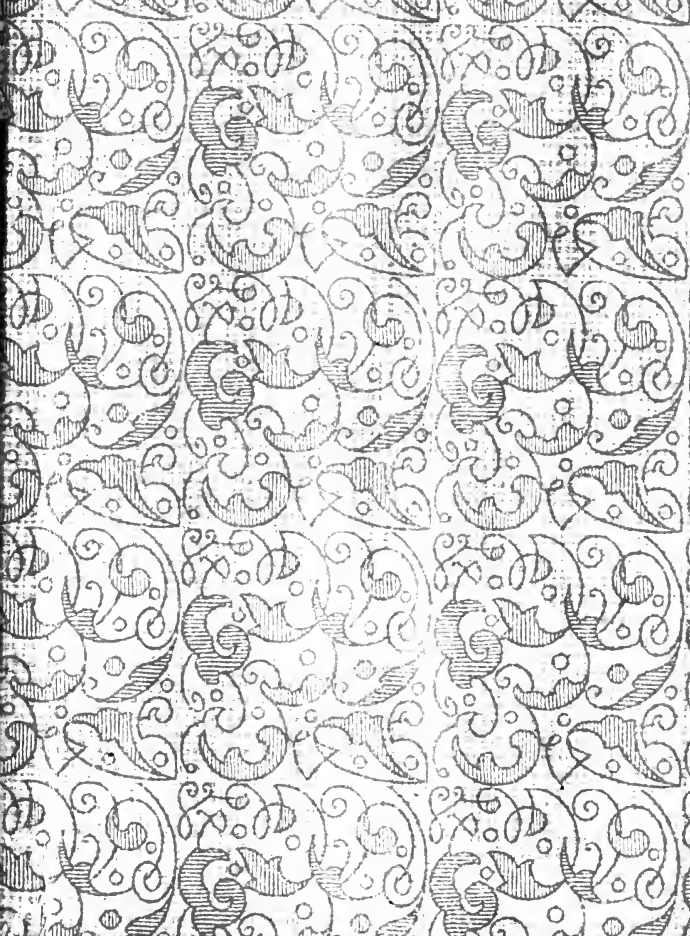

(3)

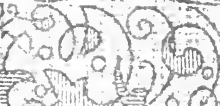

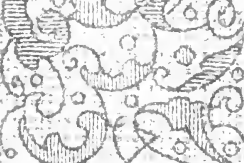






\section{AN OUTLINE}

INTRODUCTORY TO

\section{KANT'S}

\section{"CRITIQUE OF PURE REASON"}

BY

R. M. WENLEY

Professor of Philosophy in the University of Michigan
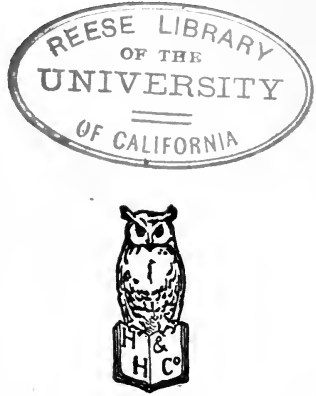

NEW YORK

HENRY HOLT AND COMPANY

I 897 


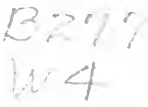

\section{$69645^{-}$ \\ Copyright, 1897,}

BY

HENRY HOLT \& CO.

ROBERT DRUMMOND, ELECTROTYPER AND PRINTER, NEW YORK. 


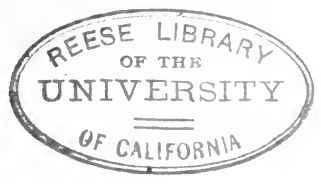

\section{PREFACE.}

THIs little book is entirely experimental. In the practical work of teaching I have found that students, when about to undertake first-hand consideration of a classical text, are apt to be sensibly handicapped by lack of a general conspectus of its contents. It seems that need exists for a pedagogical aid designed to meet this want, and several colleagues have confirmed me in this idea. The main difficulty is to supply exactly what is required and, at the same time, to refrain from giving too much. For it is unquestionable, judging from past experience, that some works, similar in kind, have come to be regarded as "short-cuts." Students have been tempted to substitute the account of the text for the original article. Accordingly, the aid must be general, and also no more than the merest introduction.

In these circumstances, my object is easily stated. I desire to furnish, in the simplest possible form, an outline of the contents of the "Critique of Pure Reason," and to show, with similar generality, how the book came to be written at all. My intention is that this sketch should be mastered by pupils immediately before they proceed to deal with the text. It is designed to enable them to see where their author is going. My hope is that it may be brief 
enough not to afford even passable excuse for omitting careful study of the original, and sufficiently interesting to provoke curiosity. I have endeavored to break the matter down as much as possible; and, al-

- though Kant's main lines are naturally pursued, I have not scrupled to introduce such modifications as appeared to me to render the argument more easy of apprehension. Pains have been taken to eliminate technicalities, and an attempt has been made to confine the use of philosophical terms as far as may be to those explained in the course of the outline.

In the peculiar case of the "Critique of Pure Reason" this outline may also prove useful as an exercise in analytic processes for students who are beginning the study of philosophy.

Should this little book command a public-in other words, should its underlying idea be approved by my colleagues in other universities and collegesit is the publishers' and my intention to include in a series similar accounts of the leading philosophical masterpieces. To this end we hope to enlist the services of prominent teachers in America and Britain.

I have to thank my colleague, Professor Alfred H. Lloyd, for reading the manuscript, and for several valuable suggestions which I have adopted. At his instance I have added the brief list of terms given at the end.

\section{R. M. Wenley.}

Ann Arbor, Mich.,

July 19, 1897. 


\section{CONTENTS.}

PAGE

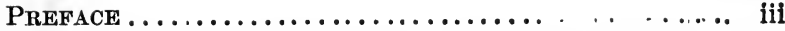

The Genesis of “The Crittque of Pure Reason "... 1

The Problem of “The Critique of Pure Reason".. 21

Outline of the Contents of the "Critique of

PuRe Reason "............................ 28

The Contents of the "Critique of Pure Reason"

Introduction ........................... 32

Transcendental Asthetic..................... 36

Metaphysical Exposition of Space and Time.... 39

Transcendental Exposition of Space and Time... 40

Transcendental Analytic................... 42

Discovery of the Categories ................ 43

Deduction of the Categories................. 45

Schematism of the Categories............... 52

Transcendental Dialectic...................... 63

Rational Psychology...................... 67

Rational Cosmology ...................... 71

Rational Theology........................ 79

Conclusion ................................. 85

Books..................................... 87

TERMS .......................................... 89 



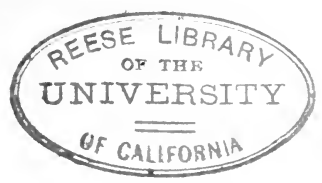

\section{KANT'S “PURE REASON.”}

\section{THE GENESIS OF THE "CRITIQUE OF PURE REASON."}

THE greatest name in the history of philosophy immediately preceding Kant is that of David Hume (fl. 1\%40-79). His office was to sum up and settle the account of previous thought. In various ways the thinkers who went before him had not been altogether faithful to the assumptions from which they started. Hume tried to correct this error and, on the basis of certain unexamined principles, to estimate the value of human experience. The elements taken for granted by him may be summarized as follows. (1) The method of inquiry. This is usually known as individualistic and introspective. That is to say, an examination is made, not of knowledge in general, but of its constitution as traceable in this man or that. Reflection turned by the individual mind upon itself furnishes the principal source of information. Each one, as it were, stands by himself in the realm of knowledge, and is responsible for his own requirements and contribution to the common stock. This is plainly illustrated by one of the chief difficulties of Hume's constructive theory. He supposes that the complexity 
of experience is to be accounted for by the operations of association hardened into permanency by habit; but this process begins afresh in every life, and, within the narrow span of the individual's career, it must originate and complete the syntheses necessary to knowledge. Here the idea of heredity, one offspring of the doctrine of evolution, has no place; and, similarly, the conception of the solidarity of experience, so conspicuous now, holds no prominence. (2) Like his predecessors, Hume accepted what is commonly known as the "two-world" theory of Descartes. Thought and extension-mind and matter, as we should now say-are two separate spheres. Not only this; they are actually opposed to each other. Neither possesses any quality in common with the other. A great gulf is fixed, and the main problem of philosophy naturally stands closely connected with the undoubted bridging of the chasm which does take place in experience. (3) Given this dualism, the question necessarily occurs, How can knowledge get into mind? It must either originate there, according to the doctrine of innate ideas or intuitionalism, or it must come in through the medium of the senses. As concerns Hume, the latter of the alternatives exercised paramount influence. So his third assumption was that all knowledge is ultimately referable to sensation. No idea has any value unless it can be carried back in an analysis to the impression from which it took origin. All notions that are too complex for this sensational reference are to be set down as illusions, which, in turn, can be, not explained, but explained away. The chief 
representative of this mode of approaching the problem was Locke. (4) But, as every one knows, there is an old proverb that runs, "Every man to his taste." And, if impressions be the basis of knowledge, it must apply in thought as well as in matters of mere taste. In other words, each man is confined to the states of his own consciousness. Berkeley adopted this position, especially in his early thought, and developed it in an intellectual rather than a sensational direction. For him nothing exists save. "spirits and their modes." Thinking beings and the ideas that emanate from them constitute the sole realities. Hume's data, then, may be summarized in the three terms, Individualism, Dualism, Sensationalism. His predecessors, however, employed these assumptions mainly as starting-points, and, as necessity pressed, admitted, for the most part unconsciously, the presence of other elements. Descartes finds that Deity is a tertium quid so functioning as to render matter and mind factors organic to a single experience. Locke does not rest satisfied with his sensationalism, but introduces a metaphysical hier- archy of primary qualities of body and of substance. Berkeley, too, finds it impossible to account for the unity of experience by reference to mere modes of thinking beings, and, to supplement them, uses other thinking beings, whom all know as "notions," in addition to the original ideas or modes of the individual consciousness; while, to explain the sameness of these many thinking beings, the conception of God is necessary. Hume's ideal was to rid thought of these inconsistencies; given the presun. $x$ 
positions, what are the sole logical deductions? This is his question.

In view of the consequences he deduces from these presuppositions, Hume is ordinarily termed a skeptic. But this name requires to be interpreted in his case. $\mathrm{He}$ is no skeptic for the sake of skepticism. He is not irreligious, or rationalistic, or blasphemous; the usual associations of skepticism hardly apply to him. He ought rather to be regarded as an intellectual skeptic. His aim is to put himself in a position to "unmake" knowledge. If the operative ideas whereby experience is elaborated and held together be no more than variations of original simple impressions, then one can reduce them to their proper level by application of the method of analysis. This enables man to rid himself from the incubus of those illusions wherein all his more complicated and so-called spiritual life finds origin. "The only method of freeing learning at once from these abstruse questions is to inquire seriously into the nature of human understanding, and to show from an exact analysis of its powers and capacities that it is by no means fitted for such abstruse questions." In this way Hume reduces knowledge to its lowest terms, and shows that, on the basis of the assumptions made by his predecessors, no other conclusion is logically tenable. The universe, subjective knowledge, and objective reality disappear beneath the touch of his hand. The constructive conceptions of God, of Self, and of Cause are proved to be, not simply the work of imagination, but of the imagination operating upon delusions which it has 
itself previously conjured up. Every effect, as Hume says, is different from its cause, if we set out with isolated impressions as data. It cannot be discovered in the cause. There is nothing in any object taken by itself which can afford us a reason for drawing a conclusion beyond it. Starting with indifferent "side-by-sideness," or indifferent sequence, if such a phrase be permissible, the indifference must remain the prominent feature till the end. Things may be "conjoined," they can never be necessarily " connected." Impressions do become conjoined by association, and habit bolsters this conjunction up till it assumes a certain permanence and furnishes a foundation for further complexities. But the fact that impressions are the all-in-all remains and cannot be surmounted. This criticism is capable of application in every corner of experience; nothing is too complicated or too sacred to escape it. Personality, religion, science-all disappear into the inane before it. Given the presuppositions, and the result inevitably follows. Consequently it avails nothing to attack the argument in the course of its procedure. The starting-point must be examined. Is it true that all knowledge comes from impressions? Do the conceptions of the universe, which this question implies, stand capable of defence? In other words, are they actually thinkable, can they be for an experience such as man's? We shall see that the problem came to strike Kant in this way. His reply to Hume is, not a disproof of skepticism, but a fresh analysis of the elements that cannot but enter into thought. $\mathrm{He}$ does not seek to rebuild 
the universe in such a way as to make it secure against the skeptical assault. But, admitted that man has the experience which he possesses, Kant asks, what elements must necessarily have entered into its constitution? To understand this, we must inquire briefly, and in general outline, into Kant's own life and environment.

With a united Germany wielding the headship of Europe, with an educated Germany leading the world in scholarship and science, it is difficult for one to realize to-day the condition of Prussia and the other states of the new empire during the second and third quarters of last century. Napoleon's crushing blow at Jena had internal as well as external causes. Culture had died down; the endless subdivisions into petty monarchies and dukedoms had resulted in a system of overtaxation by which the people were confirmed in a species of laborious barbarism. What light and leading there were had to be imported from France; the continual recurrence, in articles and the like, of the heading "Frederick the Great and Voltaire" is significant of the general drift. Semler, Reimarus, Garve, and Wolff-backed by the all-pervading influence of French skepticism and, to some extent, of English deism-were the popular philosophers. Wolff prepared the way for the spirit of the "Encyclopédie" as the imitations of Versailles at every tiny court made Napoleon's path smooth.

Wolff, though nominally a follower of Leibniz, had endeavored to graft on the monad theory the still more analytic processes of medieval logic. His 
ideal in philosophy was a series of formula whereby the complexity of mind and matter might be reduced to simplicity. Soul, for example, was no longer to be viewed as one element in a universe of mutually percipient entities, but was to be reduced to the level of a simple, incorporeal substance. The dogmatism wherein Hume could see nothing but blank skepticism was in Wolff's system to speak its last and most extreme word. Now it is to be remembered, at the outset, that Kant's intellectual life was nourished on this type of thought. Nay more, he was indebted for almost everything to its representatives. At Königsberg Wolffianism stood as the official teaching of the university. Schultz, one of its exponents, was Kant's earliest academic benefactor. But, as so often happens with brilliant students. the dominant thought was destined to appeal to Kant in an even more influential manner. One teacher, distinguished above the others by his force and power, moulded the growing intellect of the future philosopher and determined the course of his thought for many years. This professor was Martin Knutzen, a man apparently of unusual, if not extraordinary, talent. Although only twenty-seven years of age when Kant entered the university, he had already been a professor for six years. He was a disciple of the Wolffian school, and added to his marked ability in other ways an exceptional gift of teaching. Kant was therefore brought up in Wolffianism according to the most influential and the most enduring method. It came to him, not as a series of dry facts, but from the lips of a great teacher whose 
personality went out into the dead system, bringing it home to the pupil as a living thing-living, doubtless, the longer time, and with the profounder strength in that its sway was centred in the chivalrous devotion engendered by close personal intercourse between an able teacher and a disciple in whom future attainment was foreshadowed. Wolffianism, then, must have been a sort of gospel to Kant; it was the philosophical faith of his patron, and of his revered teacher and friend. But, as we shall see, the pressure of an age was destined to outweigh even the deepest sense of obligation to individuals.

Wolff's philosophy had several cardinal defects which, though patent enough to-day, were but gradually perceived by those with whom the eighteenthcentury spirit exercised influence.

In the first place, like the French encyclopædists and the English deists, the German illuminati were never tired of dilating upon the supremacy of the faculty termed Reason. Everything must needs be brought to the bar of man's Understanding-the discursive faculty known as $\delta \imath \alpha$ vor $\alpha$ by the Greeks, Discursus by the Romans, and Verstand by the Germans. What accords with Reason is alone true; all else is false, worthless superstition. But the final standpoint of Kant is already implicitly present in this contention. If it be true that Reason alone is able to adjudicate upon things, if it be admitted that all the contents of experience must be evaluated according to certain formulæ derived from Reason, then the entire contention of the "critical standpoint" has been admitted beforehand. The unity of 
experience-the fact that thought is one the world over, that specific ideas pervade all judgments alike, that the universe is capable of being rationalizedarises, not from sense or from external things, but from some activity of Reason whereby it unites itself with things, so constituting a binding relationship that is the basal circumstance in the possibility of knowledge. Yet Wolff strangled this assumption at its birth as it were. For, following the spirit of his age, he supposed that this universal principle was exhausted in applying the analytic laws of formal logic. But, one naturally asks, in applying logical law to what? If Reason have no other office than the analytic round of logical processes, whence come the materials that are to be analyzed ? Evidently, in the circumstances, they are not to be sought within the realm of Reason itself. They must come from some other and external sphere. Or, to put it otherwise, if Reason be purely formal, it is not supreme, nay, its manifestation is secondary to those "other things" that afford the corpus vile on which it is to operate. Your pathologist must have his subject to the very existence of his science. The relativity of Reason, its secondary character, constitutes the first major defect of the Wolffian view.

Twelve years after the death of Knutzen, but still no less than eighteen years before the "Critique of Pure Reason," we find Kant revolting against this purely formal account of Reason. At this time he instituted a distinction between what he called "Pure Thought" on the one 
hand and "Knowledge" on the other. "Pure Thought," according to his doctrine at this period, was practically the exponent of the Wolffian analysis. Its activity was in no sense creative or operative. Its task was to break up the contents of thought which had previously been supplied from some other source-obviously, of course, sensation. To this point, then, Kant was still at one with his past masters. But "Knowledge" was a second, and hitherto unperceived, content of Reason; and, so far from being analytic, it was held to involve synthesis, and this in the very nature of the case. Now, as soon as analysis is forsaken and synthesis substituted, the way is opened for a new and entirely different conception of Reason. But this resultant conception depends entirely upon the kind or nature of the synthesis contemplated. If, on the one side, it be considered a necessary antecedent of knowledge,-if, that is, mind be supposed to go through some process of its own, a process involved in the very existence of knowledge,--then we have arrived thus early at the general conception that informed the "critical standpoint" proper. Needless to say, this was hardly the kind of synthesis that Kant now had in view. On the contrary, he rather considered that the synthesis peculiar to knowledge was of the nature with which the positive sciences have now made us familiar. In other words, he was thinking more of an induction than of any other process. Here mind does not yet stand at the s centre of experience, but awaits events and, with these as basis, projects itself into a future of its own 
creation. So, for Kant at this stage Knowledge still remains chiefly a process of analysis, because the synthesis which it is alleged to involve is no more than a progress from given particulars to a supposed universal beyond them. The synthesis, in short, is a result, not a condition. Yet, even thus, it is important to note that at a time long prior to the "Critique" Kant was beginning to discover for himself something of the inadequacy of the Wolffian theory.

The second weakness of Wolffianism, and Kant's attitude towards it, bring us to a period five years subsequent to that just noticed-1768. As has been said, Wolff was nominally a disciple of Leibniz. Now, from one point of view, the monad theory of Leibniz was just as individualistic as the impression theory of Locke. The dictum that " every monad really excludes the whole universe" inevitably leads, on this side, to a universe in which everything is only conjoined. Attraction comes to be accidental; essential connection there is none, for each thing stands for itself, is, or has being, out of relation to any other object. Kant's next step is taken when he comes to a critical attitude in regard to this doctrine. He contended that, as a matter of fact, this atomistic view of things is not true; they do stand in close relations to each other. Mind, too, has something to say in respect of this connection. As in the former case, Kant's early criticism is imperfect. He did not yet see that things must stand in specific relations to one another-that even non-being cannot be known by its bare self. At this time Kant held that the relations are characteristic of the objects, because 
they are welded into one universe. They are connected as a matter of fact, because they have been built into a single universe by God. Relations are, accordingly, not qualities that inhere in things from the very fact of their existence, but they flow from the ordering laws of deity. Even this external idea was better than the irrelatedness of Wolff. But, fortunately, it is not the whole account of the situation. Kant took one other step which was to have momentous consequences. He not only departed from the atomistic standpoint of his teachers, but he came to see that there are some relations which exist owing to the nature of the case. That is, things would not be as they are but for the presence and operation of those relations known to us under the name of Space. Objects cannot be thought of at all unless they have first entered into specific relations with one another in space. This connection is fundamental, constitutive; apart from it experience would be impossible. The synthesis is not one that may or may not occur in the course of life; it is itself a presupposition of the kind of knowledge that man possesses.

The third defect of Wolffianism from which Kant revolted is, like the second, a direct result of the Leibnitian element. It arises in discussion of the problem, What is the relation between the universal and the individual? On this point Wolff unconsciously contradicts himself. The universal, or God, is an individual monad like all the rest. It is rounded off in itself and consequently excludes every other existence. Its universality comes there- 
fore to be a matter of name rather than of fact. It consists in its greatness or bigness, and this does not contain a guarantee of true universality. A double movement of thought lurks here. Either the universal is no more than a greater individual, an ox among the frogs, or, to obtain universality, it must swallow everything else. The universal either takes rank with individuals, or there are no individuals. The two conceptions are thus inherently opposed to one another, and above this opposition Wolffianism never rises. From this covert contradiction Kant revolted, and, in so doing, came very near to the "critical standpoint" proper. He made bold to declare that there is no such opposition as is here contemplated. In his view, universal and individual are alike incident to an original synthesis which, in turn, must be regarded as one of the conditions of the $\checkmark$ possibility of knowledge. When this idea first dawned upon him, Kant was no doubt inclined to regard the prior unity in a pantheistic way. It seemed to him as if some species of living principle -Weltseele-were pervading external matter, ordering both the permanent and the accidental, yet never manifesting itself after any definite fashion. Latterly, however, when he came to the "critical standpoint," he perceived that this relation between universal and individual, if a condition of experience, is not to be located in any foreign principle, but must be a property of mind itself. He was able to regard it, in short, as one of those mental principles which the oneness of Reason everywhere at once 
reveals and proves-proves in the sense that it is unable to explain it away.

To sum up. As Kant begins to realize the limitations of the system on which he had been brought up, he strives to break away from them, each time making an advance in his own constructive thought till, at length, he reaches the groundwork of the great "Critique," to which we now turn.

At the risk of some little repetition we must here ask ourselves the question, What were the various influences at work in Kant's mind just before he arrived at the "critical standpoint"? What, otherwise, were the immediate causes that led him to this new, and epoch-making, view ? To begin with, note once more the Wolffian doctrine that the activity of thought is a formal analytic process. In opposition to this, Kant had so far developed another explanation. As we have seen, he had learned for himself that, given analysis pure and simple, there cannot be any satisfactory explanation of experience. He therefore attempted what looks suspiciously like a compromise, - the distinction between "Pure Thought" and "Knowledge." Wolffianism could still claim him in so far as he held that the entire activity of "Pure Thought" is exhausted in the analytic process ruled by the laws of Identity and Non-contradiction. But he had departed from his early faith in that hę had asserted for "Knowledge" a certain power of synthesis. This faculty, he had argued, could not be were it not for a principle of connection by means of which it binds together isolated impressions. Embedded in this position lay 
the difficulty that by an inevitable logic drove Kant to adopt the "critical standpoint" properly so called. "Knowledge" is a result of experience; that is, certain events happen, certain sensations are felt, certain ideas are gained, and then the complex thing termed knowledge is gradually built up. So the question very naturally occurs, if synthesis be necessary to knowledge, how is it given in knowledge? Can a principle of unification, wanting which there would be no knowledge, be placed on the same level as any one of the individual contents of experience? Is it, like them, no more than one among the numerous other isolated units? It is to be remembered that this difficulty occurred to Kant before he had been influenced by Hume and his work. The precise character and direction of this new force accordingly demands attention.

When this question respecting the nature of synthesis first loomed upon Kant's intellectual horizon, he had decided that the principle of synthesis was to be classed with other more ordinary contents of knowledge. It grew up, as they did, in the course of experience. This provisional answer was an inevitable result of the separation between "Pure Thought" and "Knowledge." The former being completely analytic, the synthesis necessarily came from the latter, and was therefore on precisely the same level as any other empirically conditioned idea. This constituted the first step. But, still without acquaintance with Hume, Kant moved another stadium on his course. He discovered that the synthesis involved in the conception of Space could not 
be a derivative from experience; this at least must be placed on a higher level than the knowledge of any separate object existing in it. Why so ? If the synthesis called Space be obtained during the process of experience, it must be built up in one of two ways. (1) In the course of life we meet with a large number of different kinds of space and, comparing them, we find that they all possess an element in common. This we abstract, and label the abstracted idea Space. (2) Again, in the course of experience we may come to know numerous different instances of space, and by doing a small sum in addition we may ascend to the notion of Space in general. That is, by adding these different instances to one another we arrive at an ampler conception. But Kant saw by his own inward light that the conception of Space is not derived in either of these ways. It is not a mere result of experience, but a constitutive condition. The fact of objects in space, like the fact of different instances of space, presupposes one general Space. Kant, consequently, argued that an examination of the judgments of perception in regard to extended objects reveals the circumstance that Space possesses an existence in its own right apart from which the presence of material objects is unthinkable; that, in brief, this is the prior condition of the possibility of $\checkmark$ that divisible complex, the material universe. Without this determining or operative conception, experience as we know it would be impossible.

At this juncture, then, and in opposition to his traditional Wolffianism, Kant had urged that Reason is not entirely analytic, and that one part of its syn- 
thetic activity cannot but be an indispensable condition of the very existence of experience. In fact, he had already introduced the thin edge of the "transcendental" wedge. Hume's influence was destined to supply the motive force necessary to drive it home.

The Scottish skeptic made it his task to explain experience away. On the basis of the assumption that all knowledge must ultimately be reduced to a question of isolated impressions, he undertook to show that the permanency and stability of experience - are no more than appearances; impressions possess no - stability, and, therefore, principles that exercise for- mative control do not exist. Among these supposed -principles, Causality is one of the most conspicuous. It lies at the foundation of all science; the belief in the - continuance of the natural order reposes upon it. Yet, like all the rest, it is nothing but an association of events which follow one another arbitrarily. A delusion it cannot but be; it is only the worse for being - a big one. The dissolution of the synthesis of $v$ Casuality by Hume woke Kant up. He still supposed that Space was the only synthesis which stood forth as a condition of the existence of experience. And here, in Hume's destructive analysis, he was brought to see that, if cause and effect be a consequence of experience, it is of imagination all compact. Kant was therefore compelled to face a new problem. Can any of the syntheses on which the unity of experience reposes be empirically derived? But, ere this question could become fully apparent, another implication had to be taken into account. The synthesis of 
Space and that of Causality are not of precisely the same kind. They stand in different relations to objects. Space may very well be a condition of experience, and yet it may not be essentially connected with any given object. In other words, even if Space be a condition of experience, the rest of the process of thought-that is, the process in so far as it is in nec- essary relation to objects-may be analytic. With Causality the case is different. Empiricism may remain a satisfactory explanation of knowledge even if Space be granted as a preliminary condition, and this because Space is not indissolubly linked with this or that thing in the outer world. But if the synthesis of Causality be unobtainable from experience, then empiricism fails; for Causality is a synthesis of objects themselves. It deals not only with "mere" ideas, but with things "external" to the thinker. Kant thus came to see that the synthesis which he held to be present in experience is not derivative in any sense. The condition which it imposes holds not only on the subjective side, like - Space, but also on the objective, like Causality. The exception which he had made in favor of Space turned out to be nothing but a first step towards the extension of a similar primacy to all such synthetic processes. Hume roused him to a sense of the imminent danger involved in his previous admissions, and forced him to extend all round the principle already known to him by his own unaided reflection.

One step onward was now to bring Kant to the "critical standpoint" proper. As before, this advance took place in connection with the emergence 
of a fresh question. The problem now occurred, How can such synthetic processes be of use in experience if they take place within the subjective circle of mind? At first sight this inquiry may appear somewhat irrelevant. Why should Kant require to ask at all whether mental syntheses are of use in experience? Of course, one might immediately reply, they are of use, because they offer the conditions wanting which there would not be any experience whatsoever. Yet, from Kant's point of view, the problem was not only relevant but even inevitable. He had adopted to some extent the "two-world" theory of Descartes. The organic con- nection of mind and matter had not suggested itself to him as it invariably does to the trained modern mind. If there be a separation, and if the synthetic processes be of purely mental occurrence, then this question obviously becomes one of the last im-portance. How can they be applied to the "external" world? Kant had gradually forced himself to declare that mind is not entirely passive in knowledge; experience could not be regarded by him any longer as a mere effect somehow induced in mind. Only one alternative remained. Mind - cannot but exercise a constitutive function. The synthetic act looms larger and larger, till, at length, it seems to assume something of the function of a - creative principle, and this in relation to objects. From this conclusion Kant was also precluded; he could not accept it in its fulness. For he held that the synthetic activities are to be classed with general notions. They did not exist for him in the form of 
special objects. Thus the pressing problem came to be, How are these purely mental facts to be rendered useful in relation to a material world from which mind naturally stands isolated? This is the final step in the progress towards the "critical standpoint" proper.

Here we break off our account for a moment in order to inquire what precise significance is to be attached to this technical phrase. Its meaning may perhaps be best explained by reference to what has just been stated. Two cardinal ideas are involved. (1) Kant had arrived at the conclusion that in knowledge there are certain synthetic activities which, like Space, are conditions of experience. The first object of a system which starts with the intention of true "criticism" must therefore be to enumerate exhaustively those various synthetic conditions whereon experience is based. (2) But, as Kant considered, these activities are characteristic of mind; and between mind and external things there is a great gulf fixed. How, then, can the mental operations be of any value in ordering an experience which at every turn seems to be brought into connection with matter? Coequal in importance with the first stands the second task of a truly "critical" system. It must proceed to show how the mental syntheses acquire value in relation to that material world which constitutes one half of the universe of experience. Kant sat down to excogitate the "Critique of Pure Reason" in order to satisfy himself on these two points. 


\section{THE PROBLEM OF THE "CRITIQUE OF PURE REASON."}

Synthesis, then, furnishes the material whereon the "Critique" must work. Accordingly, the problem that Kant attacks at the outset is found to be closely connected with what has preceded. The initial question propounded in his great work is, "How are synthetic judgments a priori possible ?" The import of this problem may be stated in some such general way as follows. As a matter of fact, one that stands in need of no proof, ye find that synthesis is present in our ordinary experience. Not only does mind become aware seriatim of the occurrences incident to daily life, but it also puts them together in such a way that it is able to survey the past, to project itself into the future. Every object in the external world, for example, derives much of its characteristic reality from the relations which mind constitutes between it and other things. Indeed, nothing stands alone; everything occupies a certain position, or possesses distinctive value, in virtue of its relations to other objects. Thus it would appear that in knowledge mind is active. For relation is not a definitely existing fact, but a product of the synthetic power of mind. This is revealed in a unifying principle which binds all things together, transforming 
their disconnection into the single harmonious whole called experience. On this ground Kant thinks that mind is characterized by the possession of a certain synthetic capacity for judging. But this is not all. The power of judgment must be regarded as also a priori. That is to say, it conditions experience, is never consequent upon it. The faculty of constituting necessary relations between objects or ideas is, in his view, a formative element; apart from it experience would not be possible. Accordingly, the necessary connection destroyed by Hume is reinstated by Kant in the form of a property of mind, or of its distinctive contribution to the formation of experience. It cannot be any longer regarded as an inference worked up in the course of life, it is no deduction based on premises supplied by empirically given data; rather it is to be taken as prior to experience in the sense that it forms the manifestation of that entity for which alone experience is. Such, then, is the general meaning of the phrase "synthetic a priori judgment."

It is needful to inquire next, what was the necessity for Kant's question? If, as a matter of fact, this synthesis be present in the most ordinary exhibitions of rational activity, why ask at all "how are synthetic judgments a priori possible ?" Kant, as has been hinted, had need to put this question, because he had already admitted that the sense impressions of Hume afford us all that we know concerningthe external world. If this be so, it obviously becomes a very essential, though a very difficult, task to learn precisely how something so immensely more 
potent than a mere series of disconnected sensations comes to be necessary even to the bare recognition of these identical sensations. Hence the problem of the "Critique" comes to be, in one aspect, the only problem; for everything depends upon the solution offered in face of it. Necessary connection exists. It is a condition of the possibility of knowledge. How does it come about; how, in the circumstances, is it possible? This furnishes Kant with his starting-point, and the presuppositions that accompany the mere statement of such a question remain with him to the end, remain long after he has shaken himself clear of the immediate difficulties peculiar to the first " Critique."

It may therefore be well to elaborate his startingpoint a little more fully. We may note, at the outset, that he does not propose what is often called a " presuppositionless philosophy." He frankly begins as a dogmatist. Hume had proved that, if all knowledge be reducible ultimately to sense impressions, then necessary connection simply passes out of experience; it does not enter into the calculation, so to speak. On this basis things may be accidentally conjoined, they can never be essentially connected. But, as Kant dogmatically puts the matter in reply, necessary connection cannot be an affair of mere delusion, because it is of daily, common occurrence. If it be a piece of imagination, then all science dis- appears into thin air; all common sense must give up its most solidly based attainments. Space, time, cause, personality, and so forth are notorious facts incident to the most fragmentary consciousness. 
The sensationalist may analyze as he pleases, he cannot explain them away. They underlie each and all of his explanations so called. To attempt to get behind them is like trying to hold one's self up by one's own waistband. Accordingly, the only important problem in connection with them ought to be sought elsewhere. Seeing that inevitably they must be taken as data, the sole question worth inquiring into is, What do they signify, or how are they possible? To what constitution of the knowing mind do they point; to what conclusions regarding the nature, ontological significance, and the consequent range or possible limitations of human knowledge? Or, to put the matter in the briefest possible way, What sort of process is knowledge, and what can and do we know? This is the problem for which the "Critique of Pure Reason" proposes to find an answer. The difficulty comes to be that of accounting for the fact of necessary connection. It is a real difficulty, because the synthetic power is a priori, while the impressions furnished by the outer world are as distinctively $\boldsymbol{a}$ posteriori.

All knowledge may thus be traced back to two sources. The a posteriori element includes all that we obtain from sense, all the material which, according to Hume, association and habit work up into the complexities of experience. / This, of course, must be regarded as entirely contingent; it cannot be considered necessary to the very being of knowledge. - On the other hand, the a priori syntheses are universal and necessary. They belong to every thinking being alike / they must furnish the operative 
element in thought, if thought is to manifest itself at all. It may, perhaps, be easy enough to explain synthetic judgments a posteriori. Everybody knows how proverbs arise; we readily see why "once bit, twice shy" holds true. But when we come to inquire why every person believes that three times twelve are thirty-six, or that thirty-six is four times nine; and believes, moreover, that so it has invariably been and so it will ever be, we are face to face with a problem that presents unperceived difficulties. It is to such problems that the "Critique of Pure Reason" is devoted. That is, it discusses principles that are not deductions from common experience, but rather underlie the very existence of -experience itself. The mere fact that there is knowledge suggests them; it suggests them, moreover, with an authority and inevitableness that we cannot escape.

Before proceeding to an analysis of the contents of the "Critique," one further point demands notice. Kant employs the term "transcendental" to distinguish the charadter of his investigations. The "Critique" contains a "Transcendental Analytic," a "Transcendental Dialectic," and so on. The word itself is surrounded by misleading associations. The usual misconception rests upon a confusion. "Transcendent" is a sufficiently familiar word, "transcendental" is not. Naturally, then, the latter comes to be viewed as if it were identical with the former. Nothing could well be further from Kant's mind, and consequently productive of complete confusion of thought in respect to his meaning. 
The "transcendent" may be taken to imply that which is above or beyond experience. Non-sense, that which cannot be formulated in any clear idea, some would regard it. And it is to be feared that not a few tend to attach this latter signification to the Kantian technical term. But the "Critique of Pure Reason," seeing that it deals more strictly with experience than many philosophical works, cannot be directed to that which lies outside of knowledge. Yet experience may be regarded from two sides. One may attend either to the product or to the process. Objects, ideas, and so forth may well be subjects of interesting investigation. But they are secondary in the sense that they depend upon the mental processes whereby they are known. This is the more fundamental aspect, because it is constitutive of the products. They may or may not be, the process cannot but be. Now when Kant employs the term "transcendental," he wishes to signify that his investigation relates to this more fundamental, or essential, side of experience. The transcendental is, for him, the constitutive. We might say, for example, that in respect of the physical world, the principle of gravitation is constitutive. Without it the material universe as we know it would not be. Yet, in our investigations, we may turn to some few of the consequences dependent upon it. These are necessarily contingent; but the principle itself cannot be dispensed with. Kant's philosophy is transcendental, because its object is to formulate a complete account of all the constitutive elements that enter into experience. The products 
of mental processes may be left to take care of themselves till we possess a satisfactory account of the principles which invariably enter into the constitution of all products whatsoever. The "transcendental," then, as employed by Kant, means the primary in experience, or that which is essentially bound up with the mental process of which knowledge of definite things is the result. 


\section{OUTLINE OF THE CONTENTS OF THE "CRITIQUE OF PURE REASON."}

\section{INTRODUCTION.}

(1) We do form synthetic a priori judgments.

(2) In what way? -

- (3) In Science.

(4) The three kinds of Science :

(a) Mathematical Science.

(b) Physical Science.

(c) Metaphysical Science.

II. Transcendental Esthetic Science).

(1) What synthetic a priori judgments are possible in Mathematical Science.

(2) Those connected with Number and Magnitude; which involve Time and Space.

(3) The Metaphysical Exposition of Time and Space.

(4) The Transcendental Exposition of Time and Space.

III. Transcendental Analytic (Physical Science).

(1) What Synthetic a priori judgments are possible in Physical Science.

(2) The Discovery of the Categories.

(A) Quantity.
(a) Singular.
(b) Particular (Plural).
(c) Universal. 
(B) Quality.
(a) Affirmative.
(b) Negative.
(c) Infinite (Limiting).

(C) Relation.

(a) Categorical.

(b) Hypothetical.

(c) Disjunctive.

(D) Modality.

(a) Problematical.

(b) Assertory.

(c) Apodictical (Demonstrative).

(3) Transcendental Deduction of the Categories.

(a) First Part of the Deduction. The Categories shown to be necessary for the determination of objects.

(b) Second Part of the Deduction. The objects determined by the Categories shown to be those given in impressions of sense.

(4) The Schematism of the Categories.

(1) The Categories must be expressed under the form of Time, because Time alone applies to all possible thoughts.

- (2) Table of the Categories as schematized 'in Time.

(A) Quantity.

(a) Affirmative schematized as Unity.

(b) Particular ..... Plurality.

(c) Universal...... Totality.

(B) Quality.

(a) Affirmative schematized as Reality.

(b) Negative....... Negation.

(c) Infinite........ Limitation. 
(C) Relation.

(a) Categorical schematized as Substance.

(b) Hypothetical... Causality.

(c) Disjunctive.... Reciprocity.

(D) Modality.

(a) Problematical schematized as Possibility.

(b) Assertory......Actuality.

(c) Apodictical......Necessity.

(5) Principles of the Pure Understanding.

(a) Axioms of Intuition (Quantity).

(b) Anticipations of Perception (Quality).

(c) Analogies of Experience (Relation).

(d) Postulates of Empirical Thought (Modality).

IV. Transcendental Dialectic Science).

(1) Is Metaphysical Science possible ?

(2) The Ideas of Reason.

(a) The Soul.

(b) The Universe.

(c) God.

(3) Rational Psychology (The Soul).

(a) The Paralogism of Rational Psychology.

(4) Rational Cosmology (The Universe).

(a) (b) The Antinomies of Rational Cosmology. The First Antinomy: Quantity.

$\begin{array}{lll}\text { "Second " } & \text { Quality. } \\ \text { " Third " Fourth " } & \text { Relation. }\end{array}$

(5) Rational Theology.

(A) The Value of the Proofs of the Being of God.

(a) The Ontological Argument.

(b) The Cosmological Argument. 
THE CRITIQUE OW PURE REASON. 31

(c) The Physico-Theological Argument or Argument from Design.

(6) Conclusion. Within the limits of Pure Reason Metaphysical science cannot be shown to be possible.

V. The Transcendental Method.

(1) The Discipline of Pure Reason.

(2) The Canon of Pure Reason.

(3) The Architectonic of Pure Reason.

(4) The History of Pure Reason. 


\section{THE CONTENTS OF THE "CRITIQUE OF PURE REASON."}

\section{INTRODUCTION.}

THe contents of the Introduction have already been so far anticipated that they may be summarized here with comparative brevity. The initial question-"How are synthetic a priori judgments possible?"-and its meaning have been considered, and we have seen how this problem was connected in Kant's mind with the destructive conclusions of Hume. A synthesis consists in putting elements together so that their isolation is overcome, and a new te gonclusion emerges, one, too, in which, owing to the operation of the synthetic act, the original self-contained data have been transformed to fresh ends. Further, synthesis tends to produce necessary and universal results. To the mere fact of occurrence, derived from sensation, there has been added, by a crea-

- tive act, an entirely different element. How has this been done; or, w.lat are the ways in which mind $t \times$ ercises this pow "which cannot be doubted, because it is in constant operation? When the problem presents itself after this fashion, it may be stated in another and more definite manner. Universality or constancy, and necessity or invariableness, are the 
characteristic marks of science. Till this stage has been reached there cannot be any science worthy of the name. When it has been reached, when we are in a position to say that such and such must invariably take place, and that, under definite circumstances, it will always happen, then we have come to the sphere properly called science. The question, How are synthetic judgments a priori possible? accordingly may be legitimately stated in the more exact and less general form, How is science possible?

Looking at the problem under this aspect, it immediately becomes apparent that there are diverse kinds of science. Upon reflection it is found possible to group these under three heads.

(1) Mathematical Science. The subject-matter of this group may be designated the general conditions of objects; those conditions which attach peculiarly neither to this nor to that thing, but under which everything equally becomes known in experience.

(2) Physical Science. This has for its special field the relations of particular objects to one another. Here we get away from mere general conditions, and are compelled to take into account the connections in obedience to which this or that group of objects, or any two objects, come to take their places as effective components of experience.

(3) Metaphysical Science. This occupies itself with the general order in which all objects are involved; that is, with the universe in its entirety and the conceptions essentially connected therewith.

As a matter of fact, synthetic a priori judgments 
are formed in all these scientific groups. All combinations of numbers are, in their result, universai and necessary. They are not obtained by counting. up single units as they happen to be met in the course of experience. They are rather syntheses which condition the possibility of a great part of mathematical science. Similarly, the axiomatic conclusions relative to the properties of geometrical figures are synthetic judgments a priori. They are conditions of certain universal and necessary conclusions relative to some ways of regarding space. So, too, in physical science, some few universal and necessary judgments are the prerequisites of the very possibility of investigation. The persistence of force, the indestructibility of matter, the ultimacy of action and reaction are specimens of this synthetic a priori power. Likewise, in metaphysics, such statements as, that every effect must have a cause, or that the world must have a history or beginning in time, are first principles of a synthetic a priori character. For this reason, then, the general question, How are synthetic a priori judgments possible? may be broken up into the three more definite problems: How is Mathematical Science possible? How is Physical Science possible? Is metaphysical science possible? The main divisions of the "Critique" are dependent upon these three problems, one major section being devoted to each.

All three, however, can hardly be said to stand on the same level. Mathematical science is a patent fact. There is no need to prove its existence. Accordingly, one is entitled to infer that there must be 
an a priori admixture in the general conditions under which all objects become such for man's experience. The same holds true of Physical science. It obviously exists; its achievements are among the most potent factors in the gradual extension of knowledge. Therefore there cannot $\mathrm{be}$ an a priori element in the special relations in which individual objects stand to each other. Kant was not in a position to take the same attitude towards Metaphysical science. His career to this point had been a progress away from metaphysic as understood by previous thinkers. It was thus necessary for him to contemplate the possibility that metaphysical science might not exist. But if it be possible, then there must be an a priori admixture in the constitution of the universe regarded as a cosmos in contradistinction to a chaos. In other words, if it be possible for man to obtain an intelligible insight into the nature of the world as a whole, then there must be an intelligence without answering to the intelligence within. But in Kant's time this was by no means obvious. One might go so far as to say that it was not evident at all, for former metaphysicians had devoted themselves to the chasing of noumena, of creations of subjective activity, without any reference to the external universe as such.

To sum up. Mathematics exists and is an intelligible science. Therefore the principles on which all mathematical results are based must be intelligible. They are necessarily derivatives from intelligence, not a posteriori information, absent at one time, and then slowly built up in the course of 
the isolated occurrences incident to the progress of experience. Precisely in the same way, because Physical science possesses its definite record, the conclusion cannot be avoided that the Principles of Pure Understanding, presupposed by all physical scientists, must be actually in control of the material universe. Things, that is, are not mere things, but are what they are in virtue of an intelligible element indissolubly bound up with their being for us. With Metaphysics the case is somewhat different. Such is the condition in which that science finds itself that we are compelled to inquire, Are the ideas which lie at the base of all speculation also the ideas in accordance with which the cosmos is framed?

\section{TRANSCENDENTAL RESTHETIC.*}

In order to discover how synthetic a priori judgments are possible in mathematical science $/$ which they are, seeing that mathematical science exists 7 it is necessary to inquire, What are the contents of mathematics? Now this science treats entirely of subjects which may be divided into two great classes, viz., (1) Number, (2) Magnitude. The inquiry thus comes to be, in the first instance, How do we constitute number and magnitude? Number is constituted by the continual repetition of units, magnitude by the juxtaposition or coexistence of units. But each of these acts takes place under specific conditions. The repetition of units depends upon the presup-

* It is to be remembered that Kant here thinks of Mathematics as meaning mainly Geometry. 
position of time; the coexistence of units cannot take place unless they be distributed in space. The consequences are that Space and Time furnish the subject-matter of mathematics. Every mathematical judgment involves one or the other or both. Hence it is to be inferred that these elements are, or are intimately connected with, the possible a priori kinds of synthetic judgment in mathematics. In other words, one is forced to view them, not as special objects, but as judgments of the mind. This conclusion impresses itself upon us because of the universal validity of time and the objective universality of space. Time does not apply to the present moment alone, but invariably from the most distant conceivable past, through the present with its quickly successive experiences, into the most distant conceivable future. Space is not the medium only of this object now before me, but of each and all things that can be possibly denominated objective. To these principles, then, every part of experience must be referred; apart from them, the knowledge that we now possess would be utterly inconceivable. They are characterized by their presentation of the two principal qualities whereby we test synthesis and "a-priority;" - they are universal and necessary.

At this point a difficulty emerges. It might easily be alleged that, even granted the ultimacy of time and space, granted, too, that they are a priori, they ought to be classed with mere abstract ideas. Are they not among the many airy nothings woven by the mind; indeed, is it not obvious that they are empty? Were this objection valid, there would be 
an end to further discussion. Space and time, for all their universality and the rest, would cease to be of formative value. Kant accordingly proceeds to show that this contention may be proved invalid, and on two specific grounds. (1) Reverting once more to the universality and necessity with which the mind clothes arithmetical results, we may say that "somehow" out of the two notions of four and nine, a third, thirty-six, is produced. But this process is a priori, because in executing it mind does not descend into the sphere of external things, as it were, and, putting four things and nine things in a row, "count up" to thirty-six. Yet if it be alleged that the synthetic process whereby the mind gains the notion of number and the attendant idea of time results in no more than an abstract conclusion, then a further implication is involved. It is implied not merely that the mind remains within its own subjective circle, but that it cannot stray beyond this so as to be able to apply its results to particular things in the objective world. So far is this from being the case that, on the contrary, mind can not only proceed with this process in the abstract, but is able to employ it in the concrete. On this ground it must be said that time and space are not simply abstract ideas, but do apply as a matter of fact to reality. Again, supposing time and space to be abstract ideas, it is fair to conclude that they must be characterized by the qualities common to other abstractions. For, in the absence of these, it would not be possible so to classify them. Now the main characteristic of any abstraction consists in the circum- 
stance that it is derived by separating a common element from a number of concretes or particulars. If, then, the idea of space were abstract, we should be able to obtain it in the usual way. We should take a series of instances of space; in each of these we should detect the presence of a common element; then, by an effort of mind, we should substract this and erect it into our notion of space in general. But, as Kant had known long years before the "Critique," space cannot be thus obtained. There are no such things as a series of instances of space and time from which, after due comparison and consideration, the notions of space and time in the abstract can be evolved. "Space and time in the abstract" is a phrase that exemplifies the fallacy of reasoning in a circle, of "putting the cart before the horse." For we do not first of all learn the particulars and from them abstract a notion inapplicable to reality. We first have the notions of space and time; and if, thereafter, we speak of $a$ space or $a$ time, what we refer to is not an instance of either, but simply a part cut off from an original whole-the notion already indicated. In his reply to this objection Kant plainly shows the new drift of metaphysic of which he may be said to have been the originator. Out of his objections grow the two chief "critical" portions of the Asthetic.

THE METAPHYSICAL EXPOSITION OF SPACE AND TIME.

It is here required to show that, from their function in the constitution of experience itself, Space 
and Time must be both a priori and objective.

They are shown to be a priori, because they are universal and necessary. Nothing can be thought out of time; in the same way, no object can be perceived out of space. Thus, simply because they are conditions in the absence of which there would be no experience at all, space and Time are proved to be a priori. (2) But they are more than this. They are not merely abstract conceptions of the mind; they are also present in perceptive acts which involve relationships with particular objects. In other words, they are objective. And this is proved by their yery nature. They cannot be regarded as abstract notions, for no given space and no given time can be termed an instance either of space or time. They are not class notions which contain under them a large number of individuals. This is so because each special space, like each special time, is a part cut off from a prior whole. But such a statement implies that ideas of this kind are homogeneous. They may contain particulars in them as parts; they never subsume them, or take them into themselves, as instances. Accordingly, Space and Time are to be regarded as both a priori and objective. They are a priori perceptions; and this is found positively from their essential nature.

THE TRANSCENDENTAL EXPOSITION OF SPACE AND TIME.

Here the same subject is approached from a somewhat different standpoint. The proof given runs along negative, rather than positive, lines. It is re- 
to the discovery of the Categories. The Categories may be defined as forms of judgment involved in experience of the relation between objects.

\section{THE DISCOVERY OF THE CATEGORIES.}

Here we at once come upon traces of Kant's early training in Wolffianism. He is seeking for what he calls "functions of unity." That is to say, he addresses himself to the task of discovering the modes whereby things are put together in course of the elaboration experience. The faculty that enables man thus to function is termed Judgment. Now Judgment is one of the three main divisions into which the field of Formal Logic is divided. Accordingly, Kant very naturally thought that the analogy from Logic, which held in the Asthetic, would be equally serviceable in the Analytic. Simple apprehension, or the knowing of single concepts, takes place under the conditions of time; so it might be supposed that the particular relations between objects would be likely to take place, in the same way, under the forms of Judgment usually set forth by Logic. These forms of Judgment, then, Kant assumes. He does not " discover" them in any proper sense of this term, he merely adopts them much as he find; them. This was a tendency due in large part to his previous training.

Later thinker, who have shaken themselves free from the supers ition of Formal Logic, thanks very largely to Kant; own work, commonly view this procedure as a most unfortunate error. It is true 
that a search for "functions of unity" has been instituted; it is also true that Judgment is a unifying faculty. But it is not similarly true that we are looking for bare forms of unity. Now Kant thought that the forms of Judgment would afford him a satisfactory enumeration of the a priori syntheses involved in the relations which the living mind constitutes between real objects. On the basis of a separation between form and matter he sought to find in the former taken by itself solution of a problem that deals as essentially with the latter. To some extent, Kant was himself aware of this limitation. He knew that Formal Logic furnishes no more than a test of consistency; and he desired a "Transcendental" Logic, one that would afford a test of truth. But, unfortunately, truth is dependent upon matter no less than upon form. If, when all the forms of Judgment have been duly enumerated and put in their proper category classes, it be then supposed that we have set forth all the ways in which our conceptions of objects may be unified, we have fallen under a delusion. And this was Kant's assumption. He stated no more than the limitations within which such a synthesis may be made. For example, were one to sssert, "If gold is a metal, it is fusible," all that would be implied would be the condition of the inclision of the conception "fusible" in that of "gold:" No particular kind of unity is indicated, only the imitation within which a certain unity may be alle'red. Now Kant was in search, not of conditions, but of kinds, of unity. In proceeding, then, to re riew his discussion 
of the categories, we must bear in mind the restrictions which he unconsciously imposed on himself by simply confining himself to the list presented by Formal Logic, instead of going on to show actually how the categories arise in those organic interrelations which emerge successively in the course of experience. (A list of the Categories as set forth by Kant is given on pp. 28-29.)

TRANSCENDENTAL DEDUCTION OF THE CATEgORIES.

Of all notable thinkers, Kant is among the most conspicuous for use of a technical phraseology all his own. We must, therefore, inquire at this point, What is the import of the somewhat cabbalistic phrase, "Transcendental Deduction of the Categories"? As in the case of Space and Time, so here, in that of the Categories, the fact of their a priori nature, like that of their objective application, stands in need of proof. The a priori character of the Categories is self-evident. We know that they are the forms of Judgment. We also know that if Judgment were not exercised experience would be non-existent. Specifically, Judgment is a condition of experience, and therefore it is plain that its forms must be $a^{\prime}$ priori. But there is no such royal road to a solution of the second problem. The objective application of the Categories still romains a moot point. Now the Transcendental Deduction is a piece of machinery invented for the purpose of overcoming this difficulty. It is devised in order to help Kant to prove that the Cate- $\lambda$ 
gories are not only a priori, but also objective. But, in order to accomplish this aim completely, two tasks must be satisfactorily performed. (1) It must be shown, in the first place, that the Categories are indispensable for the determination of objects. That is to say, the fact that in experience thought cannot say anything of an object except it apply one of the Categories must be firmly established. It must be shown that no judgment concerning objectivity is possible unless one or more of the forms of judgment intervene. No object can become the subject of a judgment unless it be brought under a category: therefore the category must be capable of objective application. Firmly to base conviction of this constitutes the first task of the Deduction.

(2) One would naturally infer that a complete proof of this first point might suffice to demonstrate the objective validity of the forms of Judgment. But such was Kant's situation that this did not hold true for him. Simply because he had contemplated the severance of mind from matter, there was no guarantee that the Categories, even if proved thus to be objective, really were applied to the objects of which we gain experience through the medium of the senses. On the basis of the two-world theory, it may be perfectly true that no judgment can possibly be made concerning any object which does not imply the use of one or other of the Categories; but it may be true at the same time that the object so judged is a mere subjective creation quite independent of the stimuli of sensation. (Accordingly, for one in Kant's difficulty the Deduction is bound to prove not only that 
the Categories are necessary for the determination of objects, but also that the objects which they thus determine are identical with those which we know in relation to the a posteriori element of sensation) On Kant's assumptions, we have no direct knowledge of objects existing externally to us in the world; we become aware of them indirectly through the medium of sensation. Consequently the Deduction must show that the objects for the determination of which the Categories are necessary, and by the determination of which they are proved objective, are those which we come to know indirectly through the interposition of sensation. This portion of the "Critique" thus falls into two distinct halves.

\section{First Part of the Deduction.}

Here it is required to prove that the Categories are necessary for the determination of objects. The aim is to show that they are objective as well as a priori. (1) Kant proceeds to prove at the outset that, unless all objects were related to one self, there would be no knowledge. If there be no permanent ego which remains unchanged throughout the passing flux of experience, then sensation cannot be arrested, much less worked up into the elaborate complexities of knowledge. Or, to employ Kant's own technical language, objects cannot be characterized as such except by the synthesis of their manifold in relation to an identical self. By this he means that all . the varied sensations connected with an object must necessarily be held together and united by a single 
self that remains unchanged? throughout the entire course of their rapid alterations. (2) Having thus pointed out that, even to the mere naming of an object as such, an active, synthetic self is necessary, Kant next proceeds to show that the forms under which this unifying activity takes place are the Categories; that, in fact, the Categories are objective, because through them the permanent self characterizes objects as objects. From what has immediately preceded we are aware that knowledge is possible only because an identical self performs the operation of binding together passing sensations. The characteristic of this ego lies in its synthetic office How, then, is this synthesis brought about? As we have already seen, by the faculty of judgment. But Kant, following the tradition of Formal Logic, supposed that the Categories exhaust the channels through which this faculty exhausts its possibilities of action. Hence they are the forms whereby this synthesis is executed, and so they are objective in their primary nature. No doubt this can be regarded as true so far as it goes. Yet it must be remembered that Kant erred in thinking that the bare forms of Judgment supplied all the necessary Categories. He left matter out of the reckoning, and so missed what he really sought, which was, not the form of judgment, but the form of unity involved in every act of judgment. Be this as it may, however, he had taken one great step in advance. He had clearly grasped the circumstance that in judgment, the unit of knowledge, there is invariably a union of conceptions which, moreover, is not, and cannot be, given in 
sense. It is true that he arrives at the necessity for Categories and at their objective application; it is also true that his inferences imply much more than he himself was aware of. His conclusion here, then, is that the Categories are the sole forms of that faculty whereby the self-a permanent element necessary to knowledge-unifies the flux of experience so that it attains the wholeness and orderliness of knowledge. From this point of view, accordingly, the Categories must be regarded às objective; without them, there could not be any objects at all.

\section{Second Part of the Deduction.}

It is now necessary to prove that the objects for the determination of which the Categories are requisite are the objects of which we obtain indirect knowledge through the medium of sensation. We are aware that the mind must be active in the upbuilding of experience; that this activity is synthetic, in nature; that the forms of this synthesis are the Categories. But we do not know that the objects which are thus synthetized are those given through the senses under the general forms of Space and Time. Moreover, it is essential that this open question should be settled. Otherwise, it might well be that we were denizens of two worlds. One of these would be that created by the action of the Categories, the other that apprehended through sense under the conditions of Space and Time. And, if this were true, then it would become necessary to re?egate each mental experience to one or other of 
these contrasted universes ere we could definitely tell whether the Categories were, or were not, objective in their application. Kant now proceeds to discharge this new obligation; the Categories must be applied only to the material offered by sensation.

(1) In the first place, he shows negatively that, unless the Categories were applied to the matter of sense, they would have no value. This point is important as evincing his appreciation of the organic nature of experience. The Categories are potential forms which only display their power in relation to suitable material. Supposing that all our knowledge "came from within,"-that is, granting that mind were a sort of mill grinding out ideas for individual use,- then there would be no necessity for Categories. If confined within its own circle, mind is already a unity; there is nothing that stands in need of being "brought in." Consequently there is no function which a unifying process can well subserve. Consequently, because the Categories exist as forms of synthesis they must be applied to that portion of knowledge which comes to the mind, as it were, from some sphere external to itself. The a priori element is what it is only by contrast with the a posteriori. Or, to put the matter otherwise, from the very fact that they are necessary, the Categories are applied to that element in experience which is derived from sense; for sensation is the sole source of our knowledge of external objects. The Categories determine sensations and bring them to unity. They determine the matter too, and not merely the form, seeing that form has no existence 
apárt from matter. (Seeing, then, that sensation supplies the only "foreign" element in knowledge, that the Categories to be such have to be applied to some such element, it follows that they are applied to what we know of things through the medium of sense. Unless they were so applied, there would be no Categories, and they are familiar portions of our experiential equipment. Such is the negative proof.

(2) We next pass to the positive flitor that the Categories are applied to the matter of sense apprehended under the general forms of Space and Time. When we unify things in space we say that they are coexistent; when we unify them in time, we say that they are simultaneous or sequent. That is, the permanent self relates two present objects in a particular way, or it connects a past object with one now present. The mind passes through a synthetic process by means of which it binds together into. a single unity things which are not necessarily related to one another. The question thus comes to be, How is this process executed? The answer is, By the . faculty of Judgment; and this, in turn, exhibits itself in the, Categories. Hence it is obvious that the Categories are applied to the matter of sense, or, as one might otherwise say, to the objects apprehended under the forms of Space and Time. For the process ) of Judgment must apply to objects so apprehended; consequently, the Categories are applied to the world as known through the medium of sensation.

At the close of the Deduction we know that the Categories are a priori; that their activity in the process of constituting experience takes the shape 
of an application of their forms to the matter of sense apprehended under Space and Time. In brief, the Categories are now seen to be a priori conceptions. Without them the flux of sensation would possess no meaning cognizable by us. On the other hand, experience ties the Categories down; they cannot create something out of nothing. Without the a posteriori matter of sense they would be mere possibilities. Work in a mental vacuum they might; but we should not be aware of their existence, for they would not be productive of definite knowledge. Sensation and the forms of Judgment are thus indissolubly linked together. Neither looms up into the vision of man's experience in separation from the other. They may be two streams, as it were; we know them only after they have commingled. Or, as Kant himself says, "Perceptions without conceptions are blind; conceptions without perceptions are empty."

THE SCHEMATISM OF THE CATEgORIES.

This is another part of the Kantian machinery rendered necessary by the separation between the matter of sense and the forms of the mind. In the Deduction it has been proved that the Categories, or forms of the Understanding, must be applied to the matter of sense. This process is an indispensable condition of the being of experience. But it so happens that, in Kant's view, the elements incident to this process are quite diverse in their nature. Sensation comes from without in the course of ex- 
perience; it is "crass" and a posteriori. The Categories come from the mind; they are "pure" and a priori. Consequently it is impossible to apply the latter directly to the former. One might say that the two groups inhabit different spheres, and that by no known process can they pass from one to the other. The Categories are the forms of the a priori synthetic, or constitutive, power of mind. The matter of sense is the a posteriori formless stuff derived from the external world in the ordinary lapse of experience. Because the two are thus essentially diverse from one another it becomes a very real problem to understand precisely how they can be so brought into contact as to coöperate in the production of a single result. The conclusion is plain, that they cannot come, or be brought, into direct relationship. Accordingly it becomes imperative to mediate between them. And this can be accomplished in one way only. Some third element must be discovered that partakes in the nature of both the others. Matter, a posteriori characteristics, perceptions, stand on the one side; form, a priori qualities, conceptions, occupy the other. Is there any faculty that can so "schematize" either as to bring it into relation with its opposite, yet, by a strange paradox, its correlative, factor in experience? Kant thinks that there is such a faculty; and that it has the power of so treating the Categories as to render them conformable to this scheme. The office of Imagination is to "schematize" the Categories. It must act as a "go-between" for the pure a priori syntheses of the Understanding and 
the formless a posteriori matter of sense. But, before this process can be intelligently understood, we must reckon with ourselves in respect to the import of the technical term "schematism."

To schematize, then, means to make a schema. Now a schema corresponds very much to what logicians call a "general term." Take, for example, any class-notion, such as "book." When we employ the term book in the abstract, Imagination presents to us the image of $a$ book already known in the course of experience, even although at the moment the term may have no special reference. Abstraction-the pure form-and intuition-the object now and here present-are conciliated when the former is apprehended as if it were the latter. We cannot fully realize in thought the qualitie's that attach to the abstract term "humanity" unless we rest them, so to speak, upon a man. The individual object and the general idea occur together in this way. 8 In other words, we use a term which is at once general and particular.) Our example may apply to any possible book, yet we cannot "hold it up before the mind" without thinking of an individual application; this alone enables us to attain a clear notiona notion possessed of definiteness. An image of this sort, which may be called a particular doing duty as if it were a universal, Kant terms a "schema." It has in it the possibility of universal application within the class it designates, and yet it finds embodiment in a special case. (Imagination is the faculty that enables us to sustain this apparently incongruous compound. ) 
How, then, does the production of such an image by the faculty of Imagination aid us in the case now under discussion? How can it mediate between the matter of sense and the forms of the mind? According to Kant's doctrine, it would appear that knowledge is a complex of two totally different ingredients. Ere experience can take place these opposites must (somehow or other have operated upon one another, and have come to disappear, so far as their isolated existence is concerned, in a result which implies the presence of both and yet of neither in its original purity. What exactly is the process covered by the vague phrase "somehow or other" ? The solution of this difficulty is not far to seek. The perceptions which sensation supplies are at the - moment of cognition brought under one or other of the general conditions of Space and Time. It is thus plain that, even if the matter of sense contain no a priori element in itself, it still must involve such factors ere it can become matter of sense for us. To be matter of sense which enters as an effective component into experience it must be presented under the a priori conditions of Space and . Time. We may, accordingly, summarize the primary elements incident to experience as three in number. First, and lowest, the "crass" and entirely a posteriori matter of sense. Second, and highest, the pure a priori forms of the mind, the Categories. Third, and intermediate between these two, the general conditions Space and Time. These agree with the first in so far as they must be viewed as perceptions, not conceptions; they agree with the 
second in so far as they must be characterized as a priori, not a posteriori. Space and Time thus stand between the two extremes, and present elements of relationship to both. They are not a posteriori perceptions, like sensations, nor a priori conceptions, like the Categories; but they are a priori perceptions. They agree with the sense matter in perceptive character, and with the Categories in their a priori nature. It is consequently evident that Imagination, in its process of schematizing, must mediate between the extremes by using the mean. It must picture the universal Categories in such a particular way that they may fall under the general conditions of Space and Time. It will thus bring them down from the high a priori sphere, and so render them applicable in the workaday world of practical experience. If this descent can be compassed, it will become feasible to apply the once pure forms to the matter of sense.

But a fresh difficulty emerges at this juncture. Space and Time are by no means of equally wide application. Many cccurrences incident to experience have no nesessary reference to Space. On the other hand, no part of experience whatsoever can take place outside of the conditions laid down by Time. It thus happens that the operation of Imagination in schematizing the Categories would be of imperfect effect were it confined to their expression under the form of Space. (Accordingly the phrase "Schematism of the Categories" is to be interpreted as implying their restatement by the faculty of Imagination under the general condition 
of Time. Space may be dismissed as insufficient for the purpose on hand. Imagination, then, must reproduce the Categories under the form of Time. (A list of the Categories as thus re-expressed is given at pp. 29-30.)

The Categories as Schematized.

(1) Quantity as reproduced under the conditions of Time will be indicated by the continual addition of units, that is to say, by Number. Taking number, then, and interrupting the enumeration at the beginning, we get Unity. Go on with the process of adding units and we arrive at Plurality. Grasp the units so added and treat them as if they were a single whole, and you achieve Totality.

(2) Quality, if reproduced under the limits of Time, is to be viewed as degree or the filling of time.' Thus we have Reality, or time filled; Negation, or time empty; time partially filled and partially empty, or Limitation.

(3) Relation as expressed under the form of Time comes to be order in time. Permanence in time gives us Substance. Regularity of succession in time affords Causality. Coexistence, or "side-by-sideness" in time, produces Reciprocity.

(4) Modality deals with the nature or kind of a thing, and is therefore to be expressed as conformity to the conditions of Time. This supplies, first, Possibility, which implies that the picture we frame of different occurrences of the same object conforms with the condition of Time in general. Under these 
conditions a synthesis is possible. Actuality has the implication of existence in a given time. Lastly, existence which has been, is, and ever will be is Necessity. That is, it can be identified with existence in all time.

We may here pause for a moment in order to gather up results. In the Analytic Kant has all along been thinking of Physical science. To this point two very important facts have been abundantly discussed. In the first place, it has been shown that, from the very nature of the case, our experience of the relations between particular objects contains an a priori element. Secondly, we have learned that the Categories are the forms of a priori synthesis whereby we make judgments concerning objects. Further, they are applicable to the matter of sense under the general form of Time. Having completed this survey with these results, Kant immediately proceeds to show how the principles thus elucidated apply in the actual syntheses of experience.

\section{PRINCIPLES OF THE PURE UNDERSTANDING.}

We have seen that synthetic a priori judgments are possible in Physical science. These judgments are the Categories. Now we pass to a new question. Crranted that this is the fact, what can we say of the field of Physical science-that is, of Nature,-seeing that it is subject to determination by the Categories? Or, when the Categories are applied to the objects of Physical science, what do they import? According to Kant, the Principles of the Pure 
Understanding are the synthetic a priori judgments which the Categories place us in a position to make in regard to Nature. They naturally fall into four classes, one corresponding to each of the main divisions of the Categories.

(1) The first division relates to Quantity, and is known by the name Axioms of Intuition. It is based directly on the principle that every intuition has a definite quantity. There can be no perception of objects which lack the mark of quantity. "All sensibly perceived phenomena have magnitude of extension, or are extensive quantities." This is evident from the fact that they are all in Space and Time. From this circumstance certain of the axiomatic principles of Mathematics flow. Between two points there can be only one straight line; two straight lines can never enclose a space. The application of the Categories to the world of nature, so far as Quantity is concerned, teaches us that every perception must possess a form. In other words, the methods of Physical science are strictly relative to phenomena of the external world, and are consequently inapplicable in any explanation of the process whereby this world is apprehended. This is one of Kant's most important and historically influential conclusions.

(2) The second division of the Principles of the Pure Understanding relates to Quality, that is, to the quality of the content of perception. Hence its name, Anticipations of Perception. It depends upon the underlying principle that every perception cannot but possess degree. This fact supplies us 
with a reason a priori, inevitably, for anticipating that the matter of sensation which we find in all perceptions will be measurable on account of its quality. Conception must be empty without the matter supplied by sense. Or, to vary the expression, Anticipations of Perception inform us prophetically, as it were, that it is not within the bounds of reasonable possibility that we should ever perceive nothing, although of course this will not deter some from the delight incident to perceiving the infinitely little.

These two sets of principles apply to all perceptions in general. The two following groups, seeing that they are connected with Relation and Mode, have special appositeness in connection with judgments in which particular relations between objects occur.

(3) The Principles connected with Relation are to be found in perceptions which involve one or other of the three Categories, Substance, Causality, and Reciprocity. They are termed Analogies of Experience. We judge, first, that Substance remains one and the same throughout all change. It persists. Second, we infer that every change is referable to cause. Third, we reason that all things which coexist act and react upon each other. This is but another series of instances of the truth on which Kant has been insisting throughout, namely, /that no knowledge can take place apart from the activity of the mind as evinced in a priori and determining judgments) To take substance. We say that it remains the same through- 
out all change. In other words, this is a synthetic a priori judgment which constitutes a condition of our knowledge in perception of external things. "We speak of phenomena as coexisting and succeeding each other. But coexistence and succession are modes of time, and are indistinguishable, and indeed inconceivable, except in relation to the one unchanging and permanent time which includes them both in its synthesis. So phenomena can be conceived and known as coexistent or successive, only as contained in one sum total of all phenomena, which is itself permanent and unchanging." But this implies that the a priori synthesis of a permanent substance is a condition of experience; it is an analogy from which we derive the order of experience itself.

(4) Lastly, the Principles of the Pure Understanding which deal with Modality are termed Postulates of Empirical Thought. They are the a priori syntheses of Physical science which have to do, not with the objects of knowledge usually termed " matter collectively," but with the mode or kind of our knowledge of them. The objects remain the same, but we are at liberty to vary the point of view from which we regard them. The Postulates are thus directly connected with the three Categories of Possibility, Actuality, and Necessity. They may be stated as follows : First. Anything which is consistent with the formal conditions of experience, that is, with the necessary forms of conception and perception, is possible. Second. Whatever agrees with the material conditions of experience, as given 
in sensation, is actual. Third. Anything the reality of which follows, according to the universal conditions of experience, from the reality of something else perceived to exist is necessary.

These, then, are the synthetic a priori judgments to be found in Physical science. They are inferred directly from the Categories. For this reason they are not of themselves a priori, like the general conditions of Space and Time, which seem in some sense to be pre-existent conditions of experience.j Nevertheless they are a priori as essentially if we regard them from the point of view of the results in which they are concerned. For, equally with Space and Time, they involve a permanent self which remains the same throughout all change, and which conditions experience, because apart from its constitutive, necessary, and universal activity knowledge would be entirely non-existent. While there may be a difference between such judgments as "Four times nine are thirty-six," and "I feel warm," it is certain that, in both cases equally, the statement would be meaningless apart from that reference to the unity of self-consciousness which cannot be a mere derivative of sensation, but is nothing more and nothing less than a result of experience as interrelated and unified by one abiding intelligence. Kant did not himself fully appreciate the consequences of this principle. He nevertheless enunciated it with the utmost decision. 


\section{TRANSCENDENTAL DIALECTIC.}

In the Esthetic and Analytic we have learned that synthetic a priori judgments are possible in Mathematical and Physical science respectively; and we have seen what these judgments are. In the Dialectic Kant goes on to ask the same question in reference to Metaphysical science. At the very outset he had called attention to the circumstance that this last species of science stands on a somewhat different footing from the other two. Mathematics and Physics may be termed positive sciences; they deal with real phenomena and therefore, as a matter of fact, they exist. But Metaphysical science occupies a position strongly in contrast with theirs. It is not a dweller on earth, as it were; for it has no dealings with the matter of sense. Its subjectmatter consists, not of phenomena, but of noumena. That is to say, it considers ideas of reason as opposed to affections in which sense is present. Accordingly it cannot be said to have any such objective certainty as Physics or even Mathematics. What, more precisely, are its objects? They are mainly three in number, and they are "objects" of universal import, not particular, or isolated, phenomena. The Soul or Self; the World as a whole or the Universe; God,-these constitute its proper field. From this triple division follow the three sections into which the inquiry may be separated. Rational Psychology deals with the Soul; Rational Cosmology with the Universe; Rational Theology with God. All three subjects are Ideas of Reason, and as such are to be 
set orer against the particular phenomena in which a sense element is necessarily involved.

Before proceeding to consider each of these divisions in detail, it is well to regard a little more fully the contrast between Mathematical and Physical science on the one side, and Metaphysics on the other. The former certainly do exist. The latter may not exist; in the circumstances of experience it may turn out to be impossible, and, as a consequence, the question respecting synthetic a priori judgments may be insoluble. Here, once more, an appeal can be taken to the analogy from Formal Logic. As the earlier and less complex divisions of this science correspond to the Esthetic and Analytic, so the final portion may contain a parallelism to. Metaphysics, to the Dialectic. In the Esthetic the general forms of Space and Time are also the forms under which the Simple Apprehension of concepts takes place. Similarly, in the Analytic, the forms of Logical judgment, the Categories, are the forms. under which synthetic a priori judgments in Physi-: cal science fall. The forms incident to Logic and. those incident to the a priori judgments are identi- . cal. The conditions which determine judgments in Mathematics are present also in the Logical process called Simple Apprehension; those which determine judgments in Physical science are to be found in the Logical process termed Judgment. Pursuing this analogy, it is natural to anticipate that the forms incident to the most complicated part of Logic, Reasoning, will also be discovered in the Ideas of Reason peculiar to the Dialectic. If this be true, then once 
more, and from a different point of view, the essential disparity between Physical and Mathematical science and Metaphysics will emerge. Fortunately, too, by employing this analogy it becomes easier to detect the great difference. It may be best brought home to us by means of an illustration.

Suppose one declares that "a circle is round," both Simple Apprehension and Judgment are involved. For it is impossible to characterize an object as an object unless under the general conditions of Space and Time. Moreover, it is impossible to characterize it as of a particular kind except by aid of one of the forms of Judgment called Categories. In other words, Mathematical and Physical science, so far as they contain elements incident to the Logical divisions of Simple Apprehension and Judgment, are absolutely necessary to the determination of objects as such. Unless all that this involves be implied, knowledge must remain forever impossible; the forms of Space and Time and the Categories are indispensable to even the most fragmentary consciousness. Because we /do determine objects continually, Mathematical and Physical science exist as a matter of fact; they need no further proof. Now the case is not the same with Metaphysics, because the Ideas of Reason are not conceived as being indispensable in the same way. Or, to put the argument in the language of Logic, Syllogism is not necessary to the very being of knowledge, however necessary it may be to the unification of phenomena after they have entered into the field of conscious experience. When I say that a circle is round, I merely refer this particular circle to my 
permanent self. I stand above it and characterize it as possessing such and such a nature. But suppose I next go on to reason about it, to find out principles leading to certain conclusions in respect to sectors, tangents, and the like-I am engaged in the process of relating my judgment, that it is a circle, to something beyond this particular phenomena, to something more far-reaching. I am mounting, as it were, to a higher unity. But this higher unity, say that of a general mathematical law, is by no means of such certainty as the object about which I am reasoning. Reasoning may impel me to rise from the given object to some large general principle-to the idea of a first cause, for example-to something on which all objects depend and to which they must in the last resort be referred. But reasoning can never prove this unity to be of the same obvious truth as the forms of Space and Time and the Categories, without whose presence no object would exist at all. These exist and have certainty, because exxperience is an undeniable fact; whereas the process of superimposing results upon premises which involve these forms cannot be said to possess similarly obvious truth, or truth that must be similarly regarded in every calculation. Accordingly, while Mathematical and Physical science plainly possess factual value, the same can never be said of Metaphysics-at least in the first instance. It may turn out to be an impossibility, or at best a pseudo-science. Kant, starting from these considerations, next goes on to show why, within the limits of Pure Reason, Metaphysical science does not, and cannot, exist. 


\section{RATIONAL PSYCHOLOGY.}

We have already seen, in the Analytic, that all knowledge of objects must be referred to a Transcendental Ego, to a permanent thinking subject which remains the same through all experiential change. But Soul or Self is no more than another name for this Transcendental Ego. The question, therefore, comes to be, How do we obtain any knowledge of this entity viewed as an actual object of thought? From what has been said already, it is quite plain that any such knowledge can be achieved in one way, and in this way alone. The affirmation that "I think" is the sole channel through which knowledge of the soul as an object of thought can be reached. But we naturally ask, What do "I think" concerning the Soul or Self? Rational Psychology informs me that I think of it as a permanent entity, as something that possesses unity. Further, being a unity, it must so far resemble other substances that I may say of it, "it is indivisible." But if I so characterize the Soul I am doing no more than bringing: it under one or other of the forms of the Categories. If it be a unity, to take the case on hand, it cannot but be judged such under the category of Quantity; if it be a substance, it must be so determined under the category-class of Relation. And if an object be brought under the Categories it is referred to the unity of the Transcendental Ego, to the permanent self which welds all experience together. But Soul is itself this Transcendental Ego. Consequently, when we proceed to characterize it as an object of 
thought, we fall into the absurdity of referring it to itself for its own explanation.

Kant said that when we attempt to think the Ego as an object, we find ourselves involved in a vicious circle; for we must always imply the idea of it in order to make any judgment regarding it. If, then, the error of assuming in the proof the very thing to be proved be ever present here, two further questions immediately arise: What is the cause of this mistake? Can it be surmounted or removed? Now, in Kant's view, the cause of the error is peculiar to Rational Psychology. It centres in the confusion of two distinct entities. In the procedure of Rational Psychology two distinct selves are present. There is, in the first place, the Transcendental Self which, as has been shown, is at the beginning, middle, and end of all experience, unifying it and rendering it possible. Every object that we know must be determined by this Self. On the other hand, there is the self which we are striving to regard as an object of thought. This Kant calls the Phenomenal Self. It is not to be confused with that other entity to which we refer all the objects of experience. On the contrary, it turns out to be an object that is subject to peculiar states of its own. Each individual man has states of consciousness special to himself. These are qualities of the Phenomenal Ego, and they lack the permanence and the transforming power typical of the Transcendental Ego. But in Rational Psychology, as Kant explains, we are continually confusing the two. Nay, the confusion has to be regarded as inevitable, as something 
that we cannot escape. It may be explained thus: The Transcendental Self, with its a priori possessions of Time and Space and the Categories, cannot be viewed as an individual object in the same way as a saucer or a teaspoon. It remains one throughout all change. Its matter never alters. This feature marks it off, simply because it is the condition of the existence of objects as such. But the Phenomenal Self - the self which is a particular object at a particular time - is such because it is subject to fleeting states, and so it must be regarded as occupying much the same position as the saucer or the teaspoon. Yet, by an inevitable confusion, we transfer to mere passing states of the Phenomenal Self as an object all the permanency which characterizes the Transcendental Self in its office as the permanent element in experience. This confusion constitutes what Kant technically terms the Paralogism of Rational Psychology.

As a matter of fact, one cannot regard the Transcendental Self as an object. It is never such; for it is what it is because it must invariably be regarded as the Subject-that by the very existence of which alone anything can be said to be an object. But if we say that the Soul may, by means of the "inner sense," be made an object of knowledge in Rational Psychology, we can do so only by declaring that, as an object, it possesses certain qualities, for no object could be such unless it had qualities. So the Paralogism is this: the qualities which are absolutely essential to the determination of the Soul as phenomenal must be derived from the Transcen- 
dental Self with which this new Phenomenal Self has literally nothing in common. The insoluble difficulty thus arises. It is impossible to determine the Soul, viewed as the unity of self-consciousness, by the aid of any one of the Categories or of any combination of them. For its very nature centres in the fact that it furnishes the source whence the Categories proceed; they depend upon it for bare existence. Yet, on the other hand, if Self be regarded as a phenomenon, as one object which exists among others in experience, then it becomes not only possible but necessary to apply the Categories. to it. In the case of the Transcendental Self this application simply cannot take place; in the case of the Phenomenal Self it may occur. And with what result? The knowledge that we gain of the soul in Rational Psychology by means of applying the Categories does not afford us any information whatsoever about the Soul in its most real life. We may know as it seems at a given moment, never as it actually is. For the essential point with regard to the Self is that it is a subject, not an object. If, then, we can know it only as an object, we obtain no insight into its real, or noumenal, nature, and are therefore as far off as ever from any explanation of the synthetic a priori judgments which are possible in this, the initial, portion of Metaphysical science. Moreover, so long as we remain within the realm of Pure Reason we cannot avoid committing the Paralogism, and are thus for ever condemned to ignorance, or to inability to solve the problem which demands explanation. Rationally, we must remain. 
agnostics in regard to the Soul. Morally, as Kant was afterwards to show, we find ourselves in a position to surmount the difficulty.

\section{RATIONAL COSMOLOGY.}

When Kant comes to treat of the Universe, the same difficulty naturally occurs: is it any more possible to satisfy the demands of Reason for an objective view of the world as a whole than to present it with a phenomenal knowledge of the Transcendental Ego? "Rational Cosmology deals with the idea of the world as a totality of phenomena in one time and space. In this world, as transcendental Logic has shown, every phenomenon is determined in relation to other phenomena. It is determined in time by relation to preceding and coexisting phenomena; in space by relation to coexisting phenomena; and except through such relations it could not be determined as an object at all. Yet such determination is never complete and final; for the determining phenomenon requires to be determined by another phenomenon, and that by another, and so on ad infinitum. If, then, reason demands a complete and final determination of objects in the phenomenal world, it demands something which, in this region of knowledge at least, can never be attained. For here every answer gives birth to a new question, and no conclusive answer can ever be given." By the very fact that we are just now discussing the possibility of Metaphysic, it is proved that reason wants to unite every judgment that is made with 
every other, and so to form a completed system of the universe. "Now the peculiarity of the problems of reason which are connected with this idea is that they immediately take the form of dilemmas. They offer us the choice of alternatives, in one or other of which, according to the law of excluded middle, truth must lie. The "unconditioned totality of phenomenal synthesis," that is, the union of all particular unities, or facts, in our experience into one great unity which cannot become one object among the others that we know, "must consist either in a finite or an infinite series, in a series which has, or one which has not, a beginning. In the former case we can reach totality only by discovering the unconditioned condition which forms the first member of the series; in the latter case we can reach totality only by summing up the series of conditions, which, as infinite, is unconditioned." (Caird's Phil. of Kant, vol. ii. pp. 30-40.) In these circumstances reason finds that one of two courses is open to iteither the apparently impossible task of reaching a first cause is set, or the equally impossible one of summing an infinite series. And this at once leads to the characteristic peculiarity of Rational Cosmology. Just as the Paralogism of Rational Psychology inevitably results from the attempt made by reason to view the Soul as an object of knowledge, so in Rational Cosmology the effort put forth to grasp the world as a whole gives rise to what are called Antinomies.

Before proceeding to discuss these in detail we must try to understand what the term means. An 
antinomy bears close relation to what logicians call a dilemma. But whereas, in a dilemma, we are usually presented with two propositions both of which are false, in an antinomy we have two mutually exclusive statements each of which may be true, because it follows with as much necessity from the premises as the other. The reason why antinomies thus arise in Rational Cosmology is this: It is here supposed that the reality of the phenomenal world which we perceive around us can be made "reality" in the sense that the world is an abiding whole-which, of course, we can never perceive. In other words, "reality" in its phenomenal meaning and in its transcendental import are presumed to be capable of application to the universe in precisely the same way. The demand is that the transcendental reality should appear in our experience as if it were phenomenal. Out of this unreasonable requirement the antinomies arise.

\section{The Antinomies.}

The Antinomies are four in number, one corresponding to each of the four great classes into which the Categories are divided.

(1) The First Antinomy, or Antinomy of Quantity. When we attempt to view the world as a whole as regards its quantity, two mutually exclusive propositions can at once be proved with equal force. On the one hand, the world must have had a beginning in time, and it must be limited in space. On the other side, the world cannot have had a beginning in time, 
and it must be unlimited in space. If we accept the first of these alternatives, we must admit that there is something external to the world by which it is limited. If, on the contrary, we hold that the universe, to be a universe, must be unlimited, then we have set out upon an attempt to think the unthinkable. Kant overcomes this dilemma by pointing out that neither of the alternative propositions has any meaning in the circumstances. The predicates "limited" and "unlimited" can be applied only to things that fall within our phenomenal experience. Consequently, to try to fix them upon such a noumenon, or idea of reason, as the world in its entirety is to lift them up to a sphere where they lose all import, because they become inapplicable. Accordingly, neither of the propositions can be regarded as true, because neither is false; they merely lack all characteristics whatsoever, and so do not help us one whit to solve the problem on hand. In other words, we must conceive of the matter in this way, but in so doing we only contradict ourselves. So far as the quantity of the universe is concerned, Pure Reason can furnish us with no information.

(2) The Antinomy of Quality. Here, as before, two propositions result from any effort to grasp the quality of the universe. First. "Every composite substance in the world is made up of simple parts, and nothing exists which is not either itself simple or made up of simple parts." Second. "No composite thing consists of simple parts, and there does not exist in the world any simple substance." Briefly, the two competing conclusions are: every- 
thing is simple, and nothing is simple. When we cut a piece of wood in halves we divide it into simple parts. And it is quite clear that, from the nature of the case, every substance is capable of being divided in this way. On the other hand, the half of the original piece of wood is also divisible, and its halves divisible again, and so on, till at last a portion is reached so minute that it cannot be further subdivided; therefore the substance is incapable of division. As in the last case, Kant points out that neither of the propositions has any meaning. As before, we are applying to the noumenon, or idea of reason, standards which can be of effect only in relation to the phenomenon founded on sense material. These conclusions are our sole resources in face of the problem, but they tell us nothing. Once more the demands of Reason meet with complete disappointment.

(3) The Antinomy of Relation. Here we are on somewhat different ground. The foregoing antinomies may be termed mathematical - they deal with dead things; but here we come to consider the organic. This antinomy chiefly concerns casual relation. In other words, it faces the problem of the possibility of a first or free cause. Its thesis is as follows: "Causality according to the laws of nature is not the sole causality from which the phenomena of the world as a whole are deducible, but it is necessary for their explanation to assume also a causality by freedom." To this the antithesis immediately suggests itself: "There is no such thing as freedom, but everything happens 
purely according to the laws of nature." To prove the former, it is needful to remember that every effect must have a cause. But this cause of change is itself a change or effect, and so we are compelled to pass from it to the cause whence it proceeded, and from this once more to a third cause, and so on for ever. The permanent or unchanging cannot possibly be the cause of anything; for, if the cause do not move, it is unable to move the effect. Consequently we are unable to present causality to ourselves except as a series of changes. But because every change must be referable to a prior change, called its cause, so the entire series of causes and effects must also have a cause; and so there cannot but be a First Cause, which is what it is, because it is itself uncaused or free. But immediately we arrive at this conclusion the antithesis comes out to contradict us. For if the First Cause be in any true, or knowable, sense a cause, it must go forth from itself into its immediate effect. For this reason it is a change, not a permanent thing. Hence, according to the universal law of causality, it too cannot help being an effect. Therefore there cannot be any first cause. Here, as formerly, Kant shows that we are applying categories of the phenomenal to the transcendental; we are trying to bring the unconditioned in so as to make it bow to the terms of the conditioned. The statements that there may be uncaused beginnings of series of effects, and that every effect must have a cause, hold good only in reference to the phenomenal world of sense. When lifted up to the sphere of the noumenal they lose all 
value. The universe as a whole is not a "thing" to which causality applies. Again Reason is balked.

(4) The Antinomy of Modality. This antinomy concerns the kind or ultimate nature of the universe. The thesis is: There belongs to the universe (either as part or as cause) an absolutely necessary being. From this the antithesis at once flows: There is no necessary being either in the world or out of it The considerations whereby these two conclusions are supported are in princirle the same as in the foregoing case. And, as in the other antinomies, Kant shows that the whole situation lacks meaning. 'No information regarding the kind of world as a whole is obtainable by Reason. For Reason knows nothing but the phenomenal. It is equipped solely for the purpose of cognizing the phenomenal. Thus when it approaches the noumenal it does no more than treat it as if it were phenomenal, and consequently misses its essential nature completely.

Before quitting the Antinomies it is well to note that from one point of view the third and fourth are much more important than the first and second. Take the first, for example. In this case, where we have to consider either a limited or an unlimited universe, we are bound to suppose that, whichever alternative we choose to adopt, the world under inspection is homogeneous. That is to say, omitting the attribute of limitation, the infinite world is to be viewed as of precisely the same nature as the finite. And in the second antinomy the same may be predicated. But when we come to the third the situation is entirely different. The free cause of the 
thesis may be quite heterogeneous from the natural cause or necessitated change of the antithesis. "The elements related as cause and effect, necessary and contingent, need not, so far as they are determined by these categories, have any similarity. Hence, when we pass by the aid of these categories from the conditioned to the unconditioned, we do not necessarily regard the former as in any way like the latter." The same holds true of the fourth antinomy. Now an inference of great importance may be drawn from this consideration. We may find ourselves able to say, not, as in the case of the first and second antinomies, that both thesis and antithesis are unmeaning; but, in the case of the third and fourth, that both propositions are true, though their truth possesses application in different spheres. Take the conception of a first cause, for instance. We may hold that there must be such a cause. Now if we regard it as in all respects like the cause that we meet with in the course of phenomenal experience, we must unquestionably admit that it moves out of itself in order to give rise to an effect. In other words, we are driven to acknowledge that it is itself no more than a change; and this done, we must immediately set out in quest of its cause. But introducing the implication of heterogeneity, we at once come to see that there is no incontrovertible reason why we should thus regard the socalled first cause. By a process of reasoning we may bring ourselves to it, and then rest satisfied with our achievement. That is, it may be sufficient to gain the conviction that a first cause $i$, and superflu- 
ous to proceed to any detailed characterization of its nature. Regarding the question thus, there is no reason why the first cause must be viewed as identical in kind with the causes familiar in a posteriori experience. These causes undoubtedly bear rule in the empirical world; they determine the relations of phenomena to one another. There is no place for a first cause among them. Nevertheless the relation of the empirical world to the noumenal world may be ruled by a cause of the nature of the first cause here spoken of. Accordingly, if it is possible to show, say on moral grounds, that there is a noumenal world, which is just as real as the phenomenal sphere that experience has rendered familiar, we may at once rise to the conception of a perfectly free being as legitimately attaching to this new sphere. Kant here leaves himself a loophole of escape from the agnostic conclusions of the "Critique of Pure Reason." In the moral world man may be the denizen of another universe in which the conceptions here denied reality are the foundation facts.

\section{RATIONAL THEOLOGY.}

Rational Theology has for its main subject-matter proof of the thesis that God exists. So the question comes to be: What value can be attached, from the standpoint of Pure Reason, to the proofs usually advanced in support of this contention? These arguments may be summarized as three in number: First, the Ontological proof; second, the Cosmological 
proof ; third, the Physico-theological proof, otherwise known as the teleological proof or argument from Design.

(1) The Ontological Argument. This argument is essentially deductive in nature. Given a certain fact, it proceeds to infer another from it. The method pursued, then, is that of deducing the fact of God's being from the a priori idea of him. If man finds that the idea of God is necessarily involved in his self-consciousness, it is legitimate for him to proceed from this notion to the actual existence of the divine being. In other words, the idea of God necessarily includes existence. It may include it in several ways. One may argue, for instance, according to the method of Descartes, and say that the conception of God could have originated only with the divine being himself, therefore the idea possessed by us is based on the prior existence of God himself. Or we may allege that we have the idea that God is the most necessary of all beings-that is to say, he belongs to the class of realities; consequently it cannot but be a fact that he exists. This is held to be proof per saltum. A leap takes place from the premise to the conclusion, and all intermediate steps are omitted. The implication is that premise and conclusion stand over against one another without any obvious, much less necessary, connection. A jump is made from thought to reality. Kant here objects that being or existence is not a mere attribute which may be added on to a subject, thereby increasing its qualitative content. The predicate, being, adds something to the subject which no mere quality 
can give. It informs us that the idea is not a mere conception, but is also an actually existing reality. Being, as Kant thinks, actually increases the concept itself in such a way as to transform it. You may attach as many attributes as you please to a concept; you do not thereby lift it out of the subjective " sphere and render it actual. So you may pile attribute upon attribute on the conception of God, but at the end of the process you are not necessarily one step nearer his real existence. So that when we say "God exists," we do not simply attach a new attribute to our conception; we do far more than this implies. We pass our bare concept from the sphere of inner subjectivity to that of outer reality. . This is the great vice of the Ontological argument. The idea of ten dollars is different from the fact only in reality. In the same way the conception of God is different from the fact of his existence only in reality. When, accordingly, the Ontological proof declares that the latter is involved in the former, it puts forward nothing more than a mere statement. No proof is forthcoming precisely where proof is most required. We are not in a position to say that the idea of God includes existence, because it is of the very nature of ideas not to include existence.

(2) The Cosmological Argument may be stated as follows: "Contingent things exist-at least I exist; and as they are not self-caused, nor capable of explanation as an infinite series, it is requisite to infer that a necessary being, on whom they depend, exists." Seeing that this being exists, he belongs to the realm of reality. Seeing that all things issue 
from him, he is the most necessary of beings, for only a being who is self-dependent, who possesses all the conditions of reality within himself, could be the origin of contingent things. And such a being is God. This proof is invalid for three chief reasons. First, it makes use of a category, namely, Cause. And, as has been already pointed out, it is not possible to apply this, or any other, category except to the matter given by sense under the general conditions of space and time. If, then, we employ it in relation to Deity, we try to force its application in a sphere where it is useless, and incapable of affording any information. Once more, we are in the now familiar difficulty of the paralogism of Rational Psychology or of the Antinomies. The category has meaning only when applied to phenomena. But God is a noumenon. Second, it mistakes an idea of absolute necessity-an idea which is nothing more than an ideal-for a synthesis of elements in the phenomenal world or world of experience. This necessity is not an object of knowledge, derived from sensation and set in shape by the operation of categories. It cannot be regarded as more than an inference. Yet the cosmological argument treats it as if it were an object of knowledge exactly on the same level as perception of any thing or object in the course of experience. Thirdly, it presupposes the Ontological argument, already proved false. It does this, because it proceeds from the conception of the necessity of a certain being to the fact of his existence. And it is possible to take this course only if idea and fact are convertible with 
one another. It has just been proved that they are not so convertible.

(3) Thirdly, there is the Physico-theological Proof, popularly known as the argument from Design, the most widely accepted, yet the most faulty, of all. This argument concludes from the order and adaptation in nature to the absolute wisdom and power of its designer, just as one might argue from inspection of a machine to the skill and artifice of its constructor. This argument has also several weaknesses. If it were to lead to a God, it would only supply the idea of an architect, not of a creator. A creator makes his own materials, an architect is presented with his. The God of the argument from design would be a workman who had done his best with foreign matter, with matter which constantly thwarted his purpose; he would not be God in any full sense of this term. A God limited by matter is no God. From this another objection immediately follows. We arrive at the conception only of a very great being, one of much power, of peculiar wisdom. We do not achieve one in whom we live and move and have our being. The fact that the world is contingent leads us to the notion of a being who gives it form, and who is therefore not absolute. Now it may very well be asked: Can these defects of this proof be removed? Kant thinks that they can. They may be surmounted by proving that God is the cause of the world as well as its architect; and secondly, by showing that he is, not simply a very great being, but also one who is absolutely necessary. But in order to effect this improvement, 
the two other proofs must be requisitioned-the Cosmological to prove that God is the most necessary being, the Ontological, on which the Cosmological depends. Thus all the proofs are equally valueless, and in relation to the third idea of reason, as in relation to the others, Pure Reason can accomplish nothing in the way of satisfying its own demands.

For the purposes of the beginner, this may be taken as the close of the "Critique of Pure Reason." For the Transcendental Theory of Method is an abstract discussion of principles presupposed in what has been discussed already. Its general importance lies in the emphasis which it lays upon the importance of "criticism" as opposed to other philosophical methods illustrated in previous history.

The "Critique of Pure Reason" vindicates Space and Time as the a priori forms of synthesis found in Mathematics. It vindicates the Categories as the forms of a priori synthetic judgment found in the particular relations of objects discussed by the Physical sciences. But it completely fails to vindicate Metaphysics. So far as the conclusions reached prove anything, they tend to show that there is no subject-matter for Metaphysics to work up into scientific form. Here agnosticism is the last word.

But the Ideas of Reason which it is impossible to base firmly in the sphere of Pure Reason are afterwards vindicated in the realm of morals. It may therefore be advisable to make a brief statement, in concluding, as to the relations of Kant's three great "Critiques"-the "Pure Reason," the "Practical Reason," and "Judgment." 


\section{CONCLUSION.}

LIKE all Kant's work, this triple division of his criticism is traceable to an analytic of facts given in experience. According to the method of traditional Psychology, he divides the Self into three distinct parts, powers, or faculties. These are Intellect, Will, and Feeling. The intellectual or cognitive faculty is that power which presents facts or phenomena of sense to the thinker. These, as the "Critique of Pure Reason" is intended to prove, are in some measure subject to the laws of intelligence. The general conditions of their appearance, their particular relations to one another, are determined by an a priori, or mind-conditioned, element. But as particular things they are what they are because of the matter of sense incident to them; over this the intellectual faculty has no power. So far as intellect is concerned, matter is without law. Hence the impossibility of vindicating Ideas of Reason, which extend to the universe as a whole, from the point of disadvantage incident to pure intellect.

The will, however, is that faculty whereby selfconsciousness imposes its own law upon the material world. It thus transforms what was once foreign and lawless and irrational into a neighborly, orderly, 
and morally conditioned whole. Hence within the sphere of the moral or Practical Reason it is possible

- to vindicate the demands of reason for the Soul and immortality, for the universe as an orderly whole and freedom, and, to crown all, for God.

Feeling is a faculty closely associated with æsthetic capacity. It may accordingly be called the faculty - of Taste or Judgment. In its very nature it stands midway between the purely intellectual and the purely moral. Like intellect, it receives its matter from sense in the course of experience, and this without being able to alter it so as to force it to subserve its peculiar purposes. But, after the manner of Practical Reason, it gives a law to this matter. Yet its law is not imposed, as is the moral imperative. It rather reads out what is in matter, discovers filiations not otherwise noted, perceives relations not grasped without its aid. For instance, it finds that beauty and design are implied in the world of sense phenomena; in other words, it consciously interprets - a law that is unconsciously expressed. This the faculty of Pure Reason, strange to say, cannot do. Accordingly this power of Judgment is well fitted to mend the broken universe by interposing between the world of intellect and that of sense. Thus the "Critique of Judgment" is devoted to an exposition of the faculty for design, by which the feeling element in self-consciousness is preëminently characterized. 


\section{BOOKS.}

For those who have no teacher at hand to consult, the following suggestions may possibly be useful. They are not meant to exhaust even the leading works which the real student of Kant ought certainly to master ; they may serve, however, to guide beginners.

(1) Texts. The classical editions of Kant's works are those of Rosenkranz and Schubert (12 vols.,183842); of Hartenstein (second edition in 8 vols., 186769); of Kirchmann (8 vols., 1868). Kehrbach's editions of the three "Critiques" singly, and Erdmann's edition of the "Kritik der reinen Vernunft," are useful.

(2) Translations. The translation by Professor Max Müller is the best (second edition in one volume; Macmillan \& Co., London and New York, 1896; price \$3). The usefulness of this translation is greatly enhanced by addition of the changes introduced by Kant into the second edition of his great work-changes which have occasioned much discussion. References to the pages of the German text are also given. The "Prolegomena to every future System of Metaphysics" may be read either in the translation of Prof. Mahaffy (Macmillan) or of Mr. E. B. Bax (G. Bell, London; Macmillan, New York). 
(3) Aids. The best work on Kant in English is Edward Caird's "Critical Philosophy of Immanuel Kant" (2 vols.; Macmillan \& Co., New York, and Maclehose, Glasgow, 1889). Morris' Exposition of the "Gritique of Pure Reason" (Griggs \& Co., Chicago, 1882), Wallace's "Kant" in Blackwood's series of Philosophical Classics (1882), and Watson's "Selections from Kant" (Henry Holt \& Co., 1888) are exceedingly useful. Adamson's Lectures "On the Philosophy of Kant" furnish admirable supplementary expositions of certain points, and contain exceedingly pertinent notes (Edinburgh, 1879). The German literature on Kant is enormous; references to it may be found in Ueberweg's "History of Philosophy," vol. ii., and, less fully, in such histories as those of Erdmann, Burt, Falckenberg, and Windelband. 
SOME TERMS AND DETAILS SUPPLEMENTING THE TEXT.

$A$ priori. This means with Kant what is universally present in experience and necessary to its very existence; i.e., constitutive principles which are not learned in the course of experience, but are involved in the very fact of the existence of knowledge. Kant often speaks as if the a priori elements could be known apart from experience. The spirit of his teaching, however, is that they form part of experience as an organism, and therefore cannot be known until we have become aware of them in the course of experience is actually ours.

A posteriori. This means with Kant what is contingent in experience, what is learned as experience proceeds on its course. A posteriori facts may or may not occur in experience, and so no one of them is to be taken as in any sense indispensable to the existence of knowledge. Some, however,-though not necessarily this one or that one,-are always present, otherwise the a priori factors would not be brought into clear consciousness.

Berkeley, George; b. 1685 , d. 1753 . His most important work for the pre-Kantian development is "The Principles of Human Knowledge" (1709). 
See Prof. Fraser's “Selections from Berkeley,” and his edition of Berkeley's " Works."

Category is that which can be referred to, or enter into, a relation. Kant employs the term to designate original relations without which knowledge of particular objects would not be possible; e.g., the relation of cause and effect, of substance and attribute. This relation is referred to the synthetic action of Reason.

Dualism is the name given to those metaphysical theories which imply that matter in space exists as an object out of all relation to a thinking subject.

Empiricism is the name given to those philosophical theories which teach that human knowledge is entirely, or mainly, acquired in the course of life, and this by the action upon man through sensa$\sim$ tion of something external to his knowledge and differing from it. Empiricism is commonly based on Dualism.

Experience in its philosophical significance-which it has acquired chiefly in the Kantian school-means the sum total of human knowledge, a total in which sense and constitutive principles of mind are organically interconnected and cannot be conceived of in their separation from one another. Otherwise the term is employed to mean what man gradually learns in the course of life. Kant uses the term in both senses; as a rule, it is not difficult to determine its meaning from the context, although, as Vaihinger points out, there are exceptions.

Hume, David; b. 1711, d. 17\%6. His most important work for the pre-Kantian development is 
his " Enquiry concerning Human Understanding" (1748; German translation, 1765); his chief works are: "A Treatise of Human Nature, being an Attempt to Introduce the Experimental Method of Reasoning into Moral Subjects" (1739-40); "Essays: Moral, Political, Literary" (1742); "Enquiry concerning the Principles of Morals" (1751); "The Natural History of Religion" (175\%). The two "Enquiries" are revisions respectively of Books I and III of the "Treatise." For the "Treatise" and "Essays", see the edition of Green and Grose.

Imagination with Kant is the third "faculty," which mediates between those of Sense and Reason. It faces both ways. On the one side, like Sense, it is perceptive; on the other, like Reason, it apprehends under a priori forms. Like Sense, it is receptive and passive; like Reason, it is active and constitutive. From the standpoint of modern Psychology this part of his doctrine is open to very serious criticism. See Caird, vol. i. pp. 311, 32\%, $353,390,431, s q$.

Intuition with Kant commonly means "judgment of perception." That is, it relates to a judgment good only for the person who makes it, and having reference only to a definite fact or phenomenon now present in consciousness. See "Prolegomena," sec. 18.

Kant, Immanuel; b. 1724, d. 1804. (1) His principal pre-critical works are: "Universal History of Nature and Theory of the Heavens" (1755); "Physical Monadology" (1756). The following are specially important, as bearing on his break with 
Wolffianism: "The False Subtilty of the four Syllogistic Figures"; "The only possible Proof of the Existence of God"; "On the Evidence of the Principles of Natural Theology and Morals"; “Attempt to introduce the Conception of Negative Quantity into Philosophy" (1761-2); "Dreams of a Spirit-Seer illustrated by the Dreams of Metaphysics" (1766); "On the Rational Basis for Distinction of Regions in Space" (1768); "Dissertation on the Form and Principles of the Sensible and Intelligible World" (17\%0). See Caird, vol. i. Works of the critical period: "Critique of Pure Reason" (1781) ; "Prolegomena to every future Metaphysic" (1783); "Foundation of the Metaphysic of Ethics" (1785); "Metaphysical Principles of Natural Science" (1787); "Critique of Pure Reason" (second edition, 1788); "Critique of Practical Reason" (1\%88); "Critique of Judgment" (1793) ; "Religion within the Limits of Mere Reason" (1793); "Metaphysic of Ethics" (1797). See Caird, vol. ii.

Leibniz, Gottfried Wilhelm; b. 1646, d. 1716. The most important works for the pre-Kantian development are the "New System of Nature" (1695); "Theodicy" (1710); "Monadology" (1714). See the "Philosophical Works of Leibnitz," by George Mark Duncan; Caird, vol. i., chap. iii.

Locke, John; b. 1632, d. 1704. Principal work for the pre-Kantian development, "Essay concerning Human Understanding" (1690). See Campbell Fraser's Edition with Introduction and Notes. 
Monad. This is the name given by Leibniz to the ultimate elements of being-those which cannot be analyzed into anything more fundamental. He conceives of the Monad as spiritual, simple, selfdetermining, immaterial, self-contained, and active. It derives its characteristics from the fact that it is an active unity.

Noumenon. It may be said generally, that by this term Kant means an object of Reason, in contradistinction to phenomenon, an object of sense. If Reason be forced to infer that, throughout all experience, one self remains unchanged and operates as a principle uniting the whole, then this self, not being an object presented by any sensible experience, but being an inference of Reason, is to be called a Noumenon. In the same way, if Reason obtains from sense the matter on which it superimposes the Categories, and at the same time is compelled to infer to some thing from which the sense-matter comes, this thing, not being given in sense, but being an inference of Reason from the known facts, is to be called a Noumenon.

Objective is a term used in different senses by different thinkers. As concerns Kant, it is to be defined mainly by contrast to perception and conception. Perception takes place in relation to sense-elements; conception relates to the a priori forms of the mind. The conjunction of these two gives knowledge, which may be said to have an objective reference in so far as it informs us of things which appear to us to possess a definite character. It 
does not, with Kant, refer to ultimate reality, which, according to his theory of Knowledge, we can never know by aid of pure intellect.

Paralogism is a term used by Kant to indicate a kind of fallacious reasoning that is to be contrasted with Sophism. A sophism is a false reasoning which deceives those who hear it, but not him who propounds it. A Paralogism is a false reasoning which deceives him who employs it. In other words, it is unconscious, and may be due, as the paralogism of Rational Psychology is, to a fundamental defect of the human mind.

Phenomenon is a term used by Kant to indicate the contents of experience when viewed in their successive occurrence. If it be true that knowledge consists of sense-impressions "licked into shape" by the forms of the mind, then we do not know what really exists in an " external" world, but only what appears to us under the conditions just mentioned. Thus we know phenomena-what appears to us to be, not necessarily what actually is.

Reason with Kant means the faculty of knowledge possessed by the mind. Pure Reason means this faculty used without reference to experience, i.e., to the matter derived from sense. It relates to the conditions which mind brings with it to the constitution of experience.

Wolff, Christian; b. 1679, d. 1754. His principal systematic works notable in the pre-Kantian development are written in Latin, and are as follows: "Rational Philosophy or Logic" (1728) ; "First Philosophy or Ontology" (1729); "General Cos- 
mology" (1731); “Empirical Psychology" (1732); "Rational Psychology" (1734) ; "Natural Theology" (1736-7). What is of importance to the student of Kant is Wolff's general standpoint, rather than the details of his system. See Caird, vol. i., chaps. i-iv.

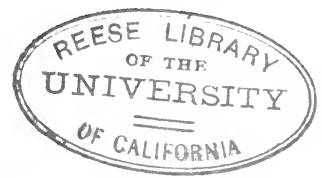


$6 a$ 



\section{DAY USE}

\section{RETURN TO DESK FROM WHICH BORROWED}

\section{LOAN DEPT.}

This book is due on the last date stamped below, or on the date to which renewed.

Renewed books are subject to immediate recall.

$$
\begin{aligned}
& \text { RE=つLU } \\
& \text { DEC } 5 \text { 1967 } \\
& 1980
\end{aligned}
$$

REC.CIR. JUN5 "80 
